Veröffentlichungsreihe der Abteilung Institutionen und sozialer Wandel des

Forschungsschwerpunktes Sozialer Wandel, Institutionen und Vermittlungsprozesse des

Wissenschaftszentrums Berlin für Sozialforschung

FS III 99-204

\title{
Die demokratische Gemeinschaft in den USA und in Deutschland
}

Dieter Fuchs

Berlin, September 1999

Wissenschaftszentrum Berlin für Sozialforschung gGmbH (WZB)

Reichpietschufer 50, D-10785 Berlin,

Telefon: (030) 2549 1-0 
Zitierweise:

Fuchs, Dieter, 1999:

Die demokratische Gemeinschaft in den USA und in Deutschland.

Discussion Paper FS III 99-204.

Wissenschaftszentrum Berlin. 


\title{
Zusammenfassung
}

Der Gegenstand der Analyse sind die politischen Gemeinschaften in den USA und in beiden Teilen Deutschlands. Auf der Grundlage einer Erörterung der kulturellen Traditionen wird im ersten Teil begründet, daß alle drei Gemeinschaften demokratische sind, daß sie aber unterschiedliche Typen dieser Gemeinschaft darstellen: die USA eine demokratischlibertäre, die alten Bundesländer eine demokratisch-liberale und die neuen Bundesländer eine demokratisch-sozialistische. Anhand von Umfragedaten des World Values Survey 1995-1997 werden diese theoretischen Annahmen im zweiten Teil der Analyse empirisch überprüft und können weitgehend bestätigt werden. Abschließend wird über die Implikationen dieser Befunde für die Entwicklung der Demokratie der USA und Deutschlands unter den neuen politischen und ökonomischen Herausforderungen spekuliert.

\begin{abstract}
Subject of this analysis are the political communities in the USA and in the two parts of Germany. Based on a discussion of cultural traditions it is argued in the first section that all three communities are democratic, but represent different types: the USA are a democraticlibertarian, West Germany a democratic-liberal, and East Germany a democratic-socialist community. Using data from World Values Survey 1995-1997, these theoretical assumptions are tested empirically and confirmed to a large extent. In the last section of the paper it is speculated about implications of these results for the development of democracy in the USA and Germany under the condition of new political and economic challenges.
\end{abstract}



Dieter Fuchs

\section{Die demokratische Gemeinschaft in den USA und in Deutschland*}

\section{Fragestellung}

Das Thema der Analyse ist eine systematische Beschreibung der kulturellen Unterschiede und Gemeinsamkeiten zwischen den USA und Deutschland im Bereich der Politik. Diese stützt sich auf repräsentative Umfragen, die im Rahmen des World Values Survey 19951997 erhoben wurden. Das Thema ist aus zwei Gründen relevant. Erstens ist die Frage, inwieweit in einem Land eine demokratische politische Kultur existiert, unter normativen Gesichtspunkten bedeutsam. Zweitens hängt das Funktionieren und die Stabilität einer Demokratie maßgeblich von der Kongruenz zwischen der durch die Verfassung implementierten Struktur und der im Staatsvolk vorherrschenden politischen Kultur ab. Wenn sich eine politische Kultur - aus welchen Gründen auch immer - soweit wandeln sollte, daß das bestehende institutionelle Arrangement nicht mehr erfolgreich unter Rekurs auf die kulturellen Werte der Bürger legitimiert werden kann, dann entsteht auch ein Anpassungsdruck auf dieses Institutionengefüge.

Der Vergleich gerade dieser beiden Länder ist unseres Erachtens von einem besonderen Interesse. Zum einen gibt es beträchtliche Unterschiede in der historischen Entwicklung. In den USA waren die politischen Institutionen von vornherein ein Ausdruck der politischen Kultur dieses Landes, so daß man von einer wechselseitigen Stabilisierung von Struktur und Kultur über einen langen Zeitraum hinweg sprechen kann. In Deutschland wurde die heute bestehende demokratische Herrschaftsordnung demgegenüber in einer zweifachen Weise importiert. Im Falle der alten Bundesländer bei der Gründung der Bundesrepublik Deutschland im Jahre 1949 und im Falle der neuen Bundesländer durch ihren Beitritt zur Bundesrepublik Deutschland im Jahr 1990. Die Frage einer Kongruenz von Kultur und Struktur ist also in Deutschland viel offener als in den USA.

Zum anderen sind die langfristigen kulturellen Traditionen in beiden Ländern sehr verschieden. Lipset (1996) kontrastiert die amerikanische und die europäische kulturelle Tradition und sieht so starke Unterschiede, daß er von einem „American Exceptionalism“ spricht. Erhebliche Unterschiede zwischen Amerika und Europa werden auch von Münch (1986) anhand einer vergleichenden Studie über England, Amerika, Deutschland und Frankreich herausgearbeitet. Wie wollen den Kern der amerikanischen kulturellen Tradition mit dem

* Der Aufsatz erscheint in: Gerhards, Jürgen (Hrsg.): Die Vermessung kultureller Unterschiede. Deutschland und USA im Vergleich. Opladen: Westdeutscher Verlag, 2000. 
Begriff des kompetitiven Individualismus und dem der europäischen kulturellen Tradition mit dem Begriff des solidarischen Etatismus kennzeichnen. Unter den europäischen Nationalstaaten verkörpert Deutschland den solidarischen Etatismus in einer besonderen Weise. Einer der Gründe dafür liegt in der Verbindung zwischen dem lutheranischen Protestantismus und der preußischen Staatsidee (Münch 1986). Der Staatssozialismus in der DDR hat diese Tradition aufgegriffen und in seiner Weise interpretiert.

Das leitende Konzept unserer Analyse ist jedoch nicht das der politischen Kultur, sondern das der demokratischen Gemeinschaft. Dieses Konzept ist u. E. für die Analyse der Stabilität und des Funktionierens demokratischer Systeme angemessener als das der politischen Kultur. Es greift grundlegende analytische Unterscheidungen der Soziologie auf und basiert auf einer Differenzierung des politischen Systems in die Ebenen der Kultur, der Struktur und der Prozesse. Das Konzept der politischen Kultur wird damit nicht aufgegeben, sondern ihm wird gegenüber dem klassischen Ansatz ein begrenzterer Bedeutungsgehalt zugewiesen. Während Almond (1980) in seinem Überblicksartikel alle politischen Einstellungen der Bürger der politischen Kultur subsumiert, wollen wir den Begriff der politischen Kultur für die Bindungen der Bürger an zentrale Werte reservieren (Fuchs und Roller 1998; Fuchs 1999). Die politische Kultur wird somit zu einer Dimension der demokratischen Gemeinschaft unter anderen. Im theoretischen Teil unserer Analyse wird zudem eine Abgrenzung der demokratischen Gemeinschaft zu den vergleichbaren Konzepten der Zivilgesellschaft (civil society) und der bürgerlichen Gemeinschaft (civic community) vorgenommen.

Die Analyse geht in folgenden Schritten vor. Zunächst wird das Konzept der demokratischen Gemeinschaft erläutert und dabei die Merkmale festgehalten, auf denen die empirische Beschreibung der beiden Länder beruhen soll. Danach folgt die Spezifikation von Erwartungen an die empirische Analyse auf der Grundlage einer Diskussion der kulturellen Traditionen beider Länder. Die empirische Analyse enthält zwei Teile: Im ersten Teil wird die theoretisch angenommene Dimensionalität der gemessenen Einstellungen und Verhaltensweisen bzw. Verhaltensdispositionen überprüft und im zweiten Teil werden die Verteilungen der Merkmale der demokratischen Gemeinschaft dargestellt. Abschließend erfolgt eine Diskussion der Analyseergebnisse in Hinblick auf mögliche politische Konsequenzen.

\section{Theoretischer Rahmen}

\subsection{Das Konzept der demokratischen Gemeinschaft}

Jede demokratische Herrschaftsordnung bezieht sich auf einen Demos. Dieser Bezug kann einen zweifachen Sinn haben: erstens als eine buchstäbliche Selbstregierung des Demos, so daß eine weitgehende Identität von Regierenden und Regierten vorliegt, und zweitens als eine Regierung des Demos, die über vom Demos gewählte Repräsentanten erfolgt (Fuchs 
1998). In beiden Fällen wird aber ein präexistenter Demos vorausgesetzt (Kielmansegg 1996). Wenn sich ein Demos selber regieren soll oder wenn er der letzte Souverän sein soll, dann muß es dieses kollektive Subjekt auch geben. Damit stellt sich die Frage, wer der Demos ist und welche Merkmale er aufweisen muß, um als Demos gelten zu können. Wir versuchen, diese Frage durch die Heranziehung soziologischer Kategorien zu beantworten.

Jeder Demos ist zunächst einmal eine gesellschaftliche Gemeinschaft (,societal community") und das wiederum ist eine der fundamentalen Kategorien der Soziologie (Easton 1965; Nisbet 1966; Parsons 1971). Eine gesellschaftliche Gemeinschaft bildet sich durch die Anwendung von zwei Mechanismen (Fuchs 1999). Erstens durch eine Grenzziehung, die definiert, wer dazugehört und wer nicht. Zweitens durch die Herstellung einer Verbindung zwischen den Individuen, die durch diese Grenzziehung einbezogen sind. Sowohl die Abgrenzung nach außen als auch die Verbindung innen muß von den Individuen (nach-)vollzogen werden, damit eine kollektive Identität entstehen kann. Erst einer gesellschaftlichen Gemeinschaft mit einer kollektiven Identität oder Wir-Identität kann ein Subjektcharakter zugeschrieben werden. Dieser Subjektcharakter ist erforderlich, damit man überhaupt sinnvoll von einer Selbstregierung dieser Gemeinschaft reden kann. Der Gesichtspunkt der Selbstregierung ist im Begriff der gesellschaftlichen Gemeinschaft natürlich noch nicht enthalten. Man kann nicht von vornherein davon ausgehen, daß jede gesellschaftliche Gemeinschaft die Demokratie als Herrschaftsform präferiert. Im Begriff des Demos ist diese Präferenz aber schon unterstellt. Wenn wir diese Prämisse übernehmen und auf die gesellschaftliche Gemeinschaft beziehen, dann handelt es sich um eine demokratische Gemeinschaft. Die demokratische Gemeinschaft ist also ein soziologischer Begriff, dessen Bedeutungsgehalt mit dem des Demos weitgehend identisch ist. Er hat inzwischen auch Eingang in die Diskussionen der normativen Demokratietheorie gefunden (Berry 1989; Chapman und Shapiro 1993).

Zur Bestimmung der Merkmale einer demokratischen Gemeinschaft beziehen wir uns auf ein Modell, das die Demokratie in drei hierarchisch angeordnete Ebenen unterteilt (Fuchs 1997a; Fuchs und Roller 1998; Fuchs 1999). Die oberste Ebene ist die der politischen Kultur, und deren konstitutiven Elemente sind die grundlegenden Werte einer Demokratie. Die nächste Ebene ist die der politischen Struktur, die aus der demokratischen Herrschaftsordnung eines Landes besteht, die in der Regel durch die Verfassung festgelegt ist. Diese Struktur kann als eine selektive Implementation der kulturellen Werte einer Gemeinschaft für den Handlungskontext der Politik begriffen werden und diese Herrschaftsordnung wird unter Rekurs auf diese Werte auch legitimiert. Die nächste und die hierarchisch niedrigste Ebene ist die der politischen Prozesse. Die politischen Prozesse beziehen sich auf die Realisierung der kollektiven Ziele einer Gemeinschaft durch das Handeln der politischen Akteure. Sie werden durch die politische Struktur gesteuert und das bedeutet unter anderem, daß mit der verfaßten Herrschaftsordnung des jeweiligen Landes normative Erwartungen an das Verhalten der politischen Akteure verknüpft sind. Die drei Ebenen stellen also eine Steue- 
rungshierarchie dar, die von der Kultur ausgeht und bei den Prozessen bzw. dem faktischen Handeln der Akteure endet. Welche Merkmale muß eine demokratische Gemeinschaft im Hinblick auf diese drei Ebenen aufweisen, damit sie als eine demokratische Gemeinschaft gelten kann?

Bei der Beantwortung dieser Frage stellt sich ein konzeptuelles Problem. Mit dem Begriff der Demokratie können unterschiedliche normative Gehalte verbunden und dementsprechend auch unterschiedliche normative Modelle der Demokratie postuliert werden (Habermas 1992a; Fuchs 1997a). Dazu gehören die Modelle der libertären, der liberalen, der sozialistischen und der republikanischen Demokratie. Um nicht von dem problematischen Anspruch der Geltung lediglich eines dieser Modelle auszugehen, beschränken wir uns zunächst einmal auf die minimalen Merkmale einer Demokratie, diejenigen Merkmale also, die die verschiedenen normativen Modelle gemeinsam haben müssen, um überhaupt als Demokratiemodell bezeichnet werden zu können (Fuchs 1997a, 1998). Wenn eine gesellschaftliche Gemeinschaft diese minimalen Merkmale akzeptiert bzw. befolgt, dann nennen wir sie eine demokratische Gemeinschaft. Auf der Grundlage zusätzlicher Merkmale im Sinne der angesprochenen normativen Modelle können wir dann diese demokratische Gemeinschaft in eine libertäre, liberale, sozialistische ${ }^{1}$ und republikanische Gemeinschaft differenzieren. Diese normativen Modelle beziehen sich zum einen auf Vorstellungen über den wünschenswerten Typ einer demokratischen Herrschaftsordnung und zum anderen auf allgemeinere Werteprioritäten, aus denen ein solcher Typ unmittelbar deduziert werden kann. Als derartige normative Modelle sind sie der Ebene der Kultur des demokratischen Systems zuzuordnen.

Wir verwenden diese unterschiedlichen normativen Modelle der Demokratie später noch zur Differenzierung der demokratischen Gemeinschaft in unterschiedliche Typen. An dieser Stelle geht es aber zunächst um die Bestimmung der demokratischen Gemeinschaft selbst. Diese ist auf der Kulturebene dadurch gekennzeichnet, daß sie die grundlegenden Werte der Demokratie befürwortet. Dazu gehören zuallererst die Idee der Selbstregierung bzw. der Volkssouveränität. Dazu gehören aber auch die wechselseitige Anerkennung der Bürger als Freie und Gleiche. Diese beiden Werte der Freiheit und der Gleichheit sind essentiell mit dem der Demokratie verbunden (Fuchs 1998). Mit Gleichheit ist im Kontext eines minimalen Demokratiebegriffs lediglich politische Gleichheit gemeint.

Auf der Strukturebene ist die Bestimmung einer demokratischen Gemeinschaft komplizierter. Diese bezieht sich - wie bereits ausgeführt - auf die konkrete Herrschaftsordnung eines Landes, so wie sie durch die Verfassung festgelegt ist. Einerseits muß von einer demokratischen Gemeinschaft erwartet werden, daß sie diese Herrschaftsordnung unter-

1 Als eine demokratische Gemeinschaft kann sich diese sozialistische Gemeinschaft nicht auf die des realen Sozialismus der Länder Mittel- und Osteuropas bis zum Ende der 80er Jahre beziehen. Es handelt sich gewissermaßen um eine ideal-sozialistische Gemeinschaft, die die Ideen der Demokratie inkorporiert und das nicht nur als Rhetorik oder Propaganda. 
stützt, sofern sie eine demokratische ist und keine autokratische. Andererseits gibt es verschiedene Möglichkeiten, eine Demokratie zu implementieren. Zu den minimalen Strukturmerkmalen gehören die Grundrechte und rechtsstaatliche Verfahren, die Gewaltenteilung, zu der immer ein Parlament als die Repräsentation des Volkes gehört, und kompetitive und periodische Wahlen. Diese Strukturmerkmale können aber ganz unterschiedlich ausgestaltet werden und demzufolge können auch schon auf der Grundlage dieser minimalen Merkmale unterschiedliche Typen von Demokratie bestimmt werden. ${ }^{2}$ Wenn die Bürger eines Landes nun den Typ der Demokratie, der bei ihnen gegenwärtig existiert, durch einen anderen ersetzen wollen, dann muß das kein Ausdruck einer mangelnden demokratischen Gesinnung sein. Eher im Gegenteil - wenn die Gründe für ihre Kritik auf der Anwendung demokratischer Standards beruhen. Die Bürger eines Landes können ihre Demokratie also aus unterschiedlichen Gründen unterstützen oder kritisieren. Sie können sie unterstützen, weil sie eine Demokratie ist und die institutionelle Ausgestaltung in ihrem Land nur eine sekundäre Bedeutung hat. Sie können sie kritisieren, weil sie die Wirklichkeit der Demokratie ihres Landes gemäß demokratischen Standards bzw. normativen Vorstellungen als unzureichend empfinden und weil sie unterstellen, daß es eine alternative Implementationsform gibt, die eine bessere demokratische Wirklichkeit erzeugt. Beide Möglichkeiten sind mit dem Konzept der demokratischen Gemeinschaft verträglich. Ihre Separierung wirft bei der Messung der Einstellungen der Bürger aber erhebliche Probleme auf.

Auf der Prozeßebene geht es um die Realisierung politischer Ziele durch die Herstellung kollektiv bindender Entscheidungen. Diese Ziele sind in pluralistischen Gesellschaften immer kontrovers und die Konflikte darüber stellen geradezu die Essenz demokratischer Prozesse dar. Eine demokratische Gemeinschaft zeichnet sich also nicht durch einen wie auch immer begriffenen Konsens hinsichtlich der zu verwirklichenden politischen Ziele aus, sondern lediglich durch die faktische Befolgung der Verfahrensnormen, die mit der Verfassung gesetzt sind und die die alltäglichen politischen Konflikte regulieren sollen.

Wenn der Sinn der Demokratie vor allem in einer Selbstregierung des Demos liegt, sei sie unmittelbar oder vermittelt, dann gehört eine Beteiligung der Bürger an dieser Selbstregierung auch zu einer demokratischen Gemeinschaft auf der Prozeßebene. Hinsichtlich der Formen und des Ausmaßes dieser Beteiligung gibt es allerdings sehr unterschiedliche Auffassungen und unter anderem darin unterscheiden sich die erwähnten normativen Modelle der Demokratie. Bei einem minimalen Demokratiebegriff ist die Beteiligung der Bürger an periodischen Wahlen ausreichend, um dem Anspruch einer demokratischen Gemeinschaft zu entsprechen. Dabei ist es eine noch zu klärende Frage, ob sich die Einlösung dieses Kriteriums immer an der faktischen Wahlbeteiligung festmachen muß oder ob eine prinzipielle

2 Es handelt sich in diesem Falle nicht um normative Modelle der Demokratie, also um Konzeptionen des Wünschenswerten, sondern um Typen realer Demokratien, die durch die Verfassungen der Länder implementiert sind. 
Beteiligungsbereitschaft genügt, die sich bei einer mehr oder weniger großen Anzahl von Bürgern unter bestimmten situativen Bedingungen auch nicht umsetzen kann.

Nachdem die Merkmale einer demokratischen Gemeinschaft festgehalten sind, wenden wir uns der Differenzierung in unterschiedliche Typen dieser demokratischen Gemeinschaft zu. Dazu ziehen wir eine Dimension auf der Kulturebene heran, die im Konzept der politischen Kultur und in der empirischen Demokratieforschung bislang vernachlässigt wurde. Es handelt sich dabei um den Ethos der Gemeinschaft. Dieser hat zwei Referenzpunkte: zum einen die ethischen Werte über die individuelle Lebensgestaltung und zum anderen die ethischen Werte über das Verhältnis zu den anderen Mitgliedern der gesellschaftlichen Gemeinschaft.

Dieses Ethos der Gemeinschaft bildet einen der Gegenstände der wichtigsten demokratietheoretischen Debatte der letzten Jahrzehnte und zwar der zwischen Liberalismus und Kommunitarismus. Wir wollen diese hier nicht in extenso erörtern, sondern lediglich die Gesichtspunkte herausziehen, die für unsere Analyseabsicht - die Differenzierung der demokratischen Gemeinschaft - wichtig sind. Die Debatte entzündete sich an dem Spannungsverhältnis zwischen der Freiheit der Individuen und den Ansprüchen der Gemeinschaft. Unterschiedliche normative Positionen machen sich vor allem an dem Vorrang fest, der dem einen oder dem anderen gegeben wird. Dieses allgemeine Kontinuum mit den Polen von Individualismus und Gemeinschaft läßt sich in die zwei Dimensionen unterteilen, die bei der Erörterung des Ethos der Gemeinschaft bereits genannt wurden. Die eine Dimension greift die fundamentale Frage auf, wer hauptsächlich für die eigene Lebensgestaltung und das eigene Lebensschicksal verantwortlich sein sollte, das Individuum selbst oder der Staat, der eine spezifische Form der Institutionalisierung von Gemeinschaft darstellt. Die andere Dimension betrifft die ebenso fundamentale Frage, wie das Verhältnis der Individuen zueinander sein sollte. Die eine Alternative ist die durch Leistung bestimmte Konkurrenz zwischen den Individuen auf verschiedenen Märkten und die andere ist ein kooperativer und solidarischer Umgang miteinander (Chapman und Shapiro 1993). Durch die Verschränkung dieser beiden dichotom gefaßten Dimensionen ergibt sich eine Typologie mit vier Ausprägungen. Dieser können die wichtigsten normativen Modelle der Demokratie und die ihnen korrespondierenden demokratischen Gemeinschaften zugeordnet werden: das libertäre, das liberale, das republikanische und das sozialistische Modell (Schaubild 1). Die durch diese Typologie vorgenommene Bestimmung von Modellen der Demokratie und der ihnen korrespondierenden Gemeinschaften basiert auf normativen Vorstellungen und ist demzufolge auf der Kulturebene des politischen Systems zu lokalisieren. 
Schaubild 1: Normative Modelle der Demokratie und Typen demokratischer Gemeinschaften

\begin{tabular}{|c|c|c|}
\hline & $\begin{array}{l}\text { Verantwortung } \\
\text { für eigenes L }\end{array}$ & $\begin{array}{l}\text { s Individuums } \\
\text { ensschicksal }\end{array}$ \\
\hline & Selbst & Staat \\
\hline Konkurrenz & $\begin{array}{c}\text { Libertäres Modell/ } \\
\text { Demokratisch-libertäre } \\
\text { Gemeinschaft }\end{array}$ & $\begin{array}{c}\text { Liberales Modell/ } \\
\text { Demokratisch-liberale } \\
\text { Gemeinschaft }\end{array}$ \\
\hline Verhältnis & & \\
\hline zueinander & & \\
\hline Solidarität & $\begin{array}{c}\text { Republikanisches Modell/ } \\
\text { Demokratisch-republikanische } \\
\text { Gemeinschaft }\end{array}$ & $\begin{array}{c}\text { Sozialistisches Modell/ } \\
\text { Demokratisch-sozialistische } \\
\text { Gemeinschaft }\end{array}$ \\
\hline
\end{tabular}

Die kontrastierenden und gewissermaßen reinen Modelle sind das libertäre und das sozialistische. Sie setzen auf beiden Dimensionen die eindeutigste Priorität zugunsten jeweils einer der Ausprägungen. Das liberale Modell unterscheidet sich von dem libertären vor allem dadurch, daß die Chancengleichheit bei der Konkurrenz zwischen den Individuen auf dem wirtschaftlichen und politischen Markt ein Gerechtigkeitskriterium ist. Und Gerechtigkeit ist wiederum der wichtigste Maßstab zur Beurteilung gesellschaftlicher Institutionen. Der prominenteste Vertreter dieses Modells ist Rawls (1993). Die Gewährleistung der Chancengleichheit kann aufgrund der ungleichen Fähigkeiten und Veranlagungen der Individuen nur durch rechtliche Regelungen und durch Umverteilungen seitens des Staates erfolgen. Der Staat bekommt somit eine starke Bedeutung für die individuelle Lebensgestaltung. Von dem sozialistischen Modell unterscheidet sich das liberale in dreierlei Hinsichten. Erstens bezieht sich die Umverteilung des Staates lediglich auf eine möglichst gleiche Verteilung von denjenigen Grundgütern, die unbedingt notwendig sind, um eine autonome Lebensgestaltung vornehmen zu können. Zweitens behält in den alltäglichen Interaktionen auf dem Markt, in der Politik und in anderen gesellschaftlichen Bereichen das Konkurrenz- und Leistungsprinzip die konstitutive Bedeutung für das Verhältnis der Individuen zueinander. Und drittens hat im Konfliktfalle die individuelle Freiheit immer einen uneingeschränkten Vorrang vor der gleichen Verteilung der anderen Grundgüter. Das bedeutet unter anderem, daß im Unterschied zum sozialistischen Modell soziale Grundrechte nicht in die Verfassung aufgenommen werden sollten. Die Gewährleistung der Chancengleichheit kann demzufolge nur 
eine politische Aufgabe sein, die praktisch zur Errichtung eines mehr oder weniger umfassenden Wohlfahrtsstaats führt. Insgesamt ist die Rolle des Staates im liberalen Modell also relativ eingeschränkter als im sozialistischen. Dieser Unterschied wird in der dichotomisierten Typologie nicht sichtbar.

Das republikanische Modell ist dasjenige, das sich von den anderen vergleichsweise am stärksten unterscheidet. Zudem kann es als das normativ anspruchsvollste betrachtet werden. Im Unterschied zum liberalen Modell haben gemeinschaftliche Werte eine zentrale Bedeutung und im Zweifelsfall auch den Vorrang vor einer uneingeschränkten Freiheit der Individuen. Die Lebensweise einer republikanischen Gemeinschaft ist „essentially cooperative and solidaristic" (Post 1993). Gegenüber dem liberalen, und vor allem gegenüber dem sozialistischen Modell unterscheidet es sich durch die anti-staatliche und antipaternalistische Grundhaltung. In dieser Hinsicht gibt es Bezüge zu dem libertären Modell. Die gemeinschaftlichen Werte sollen republikanischen Vorstellungen gemäß gerade nicht durch den Staat, und somit stellvertretend für die Bürger umgesetzt werden, sondern durch die Gemeinschaft der Bürger selbst (Etzioni 1996). Aus diesem Grunde ist die Selbstorganisation der Bürger in lokalen Einheiten ein wesentliches Postulat der Republikaner. Die republikanische Gemeinschaft ist also eine partizipatorische und solidarische Gemeinschaft. Ein wichtiges Merkmal dieser Gemeinschaft wird allerdings durch die beiden Dimensionen des Schaubildes 1 nicht aufgegriffen. Die Voraussetzung einer kooperativen Selbstregierung und einer Solidarität untereinander ist - diesem normativen Modell nach - eine gemeinsam geteilte Konzeption des Guten bzw. gemeinsam geteilte ethische Vorstellungen. Eine republikanische Gemeinschaft ist demzufolge eine ethisch homogene Gemeinschaft.

Die Gedanken einer republikanischen Gemeinschaft, die im Rahmen der normativen Demokratietheorie entwickelt wurden, sind in einem empirischen Forschungskontext vor allem von Putnam (1993) aufgegriffen worden. Er selbst verwendet den Begriff der civic community. Die von Putnam postulierten Dimensionen und Merkmale dieser Gemeinschaft lassen sich problemlos auf die von uns vorgenommenen analytischen Unterscheidungen beziehen. Putnam geht bereits davon aus, daß die Civic Community eine demokratische ist, und demzufolge auch entsprechende Einstellungen zur demokratischen Herrschaftsordnung aufweist. Bei seiner Explikation der Civic Community konzentriert er sich deshalb auf den Ethos der Gemeinschaft und das Verhalten ihrer Mitglieder, das daraus entspringt. Auf der Ebene der politischen Kultur sieht Putnam eine ganze Reihe von Werthaltungen als kennzeichnend für die Civic Community an. Er streicht zunächst den Wert der politischen Gleichheit heraus, betont aber ganz im Sinne der republikanischen Tradition, daß diese gleichen Rechte und Pflichten für alle umfaßt. Dieser Wert ist vor allem für das Verhältnis der einzelnen Mitglieder zur Gemeinschaft und ihrer Institutionen bedeutsam. Die anderen Werte beziehen sich auf die Interaktionen der Mitglieder untereinander. Diese sollen durch Solidarität, Toleranz und Vertrauen gesteuert sein. Die Bürger einer Civic Community sind 
also ausdrücklich keine egoistisch-rationalen Bürger, wie es z. B. im libertären Modell der Demokratie unterstellt wird.

Ein maßgebliches Kennzeichen einer Civic Community ist nach Putnam eine starke Bindung der Bürger an den Wert der politischen Beteiligung. Das wäre als solches auch ein Merkmal jeder demokratischen Gemeinschaft. Putnam führt aber zwei folgenreiche Spezifikationen ein. Zum einen die Gemeinwohlorientierung: ,participation in a civic community is more public-spirited, more oriented to shared benefits“ (Putnam 1993: 88). Zum anderen ist die entscheidende Partizipationsform die in freiwilligen Assoziationen. Die aktive Mitgliedschaft in freiwilligen Assoziationen trägt nach Putnam zur Erzeugung der erwähnten Werthaltungen und der damit verbundenen Fähigkeit und Bereitschaft zu einem kooperativen Verhalten zur Realisierung des Gemeinwohls bei. Das sind alles prononciert republikanische Vorstellungen. Wenn sich unsere Fragestellung aber auf die empirische Klärung bezieht, welche demokratische Gemeinschaft in den beiden Vergleichsländern existiert, dann kann die Theorie von Putnam nicht der alleinige theoretische Ausgangspunkt der empirischen Analyse sein. Putnams Studie kann aber in einer zweifachen Weise für unsere Analyse fruchtbar gemacht werden. Erstens stellt sie eine differenzierte und operationalisierte Version der republikanischen Gemeinschaft dar, und zweitens ist sie in Folge dieser Operationalisierung auch instruktiv für unsere Messungen.

Ein Konzept, das mit dem der Civic Community von Putnam erhebliche Überschneidungen aufweist, ist das der civil society (Zivilgesellschaft). Der Bedeutungsgehalt dieses Konzeptes variiert je nach theoretischem Ansatz aber beträchtlich. Dennoch kann ein gemeinsamer Fokus und somit ein konzeptueller Kern identifiziert werden. In den Varianten der Zivilgesellschaft, die in der gegenwärtigen theoretischen Diskussion ein starkes Gewicht haben, wird die Zivilgesellschaft als ein Interaktionsbereich begriffen, der zwischen oder jenseits von Staat und Markt liegt und aus einem Netzwerk von freiwilligen Assoziationen gebildet wird (Keane 1988; Cohen und Arato 1992; Habermas 1992b). Strukturell wird diese durch die Institutionalisierung von Grundrechten ermöglicht und stabilisiert. Die zivilgesellschaftlichen Assoziationen bewegen sich diesen Autoren gemäß also ,,innerhalb des institutionellen Koordinationsystems des demokratischen Rechtsstaates“ (Schmidt 1995: 566).

Insoweit ist Zivilgesellschaft ein deskriptiver Begriff, und es kann empirisch überprüft werden, in welchem Ausmaß sie in gegebenen Ländern vorliegt. Mit diesem Konzept, das auf die Denktradition von Montesquieu und Tocqueville zurückgeht (Taylor 1993), sind aber starke normative Konnotationen verbunden. Zum einen wird es von der Idee der Selbstkonstitution und Selbstmobilisierung der Gemeinschaft geleitet, die sich im gemeinsamen Handeln in freiwilligen Assoziationen vollzieht. Die Zivilgesellschaft kann in diesem Sinne als ein Ausdruck einer authentischen Selbstregierung gesehen werden. Außerdem soll sie ein Bollwerk gegen die Errichtung einer tyrannischen Herrschaftsordnung oder zumindest eine Einschränkung einer zentralisierten Staatsgewalt bedeuten. Vor allem aufgrund 
dieser der Zivilgesellschaft zugeschriebenen Eigenschaften hat sie eine große Prominenz in der Forschung über die Transition von autokratischen zu demokratischen Systemen gewonnen (Linz und Stepan 1996).

Zum anderen wird von der Zivilgesellschaft eine Gegenbewegung zu den desintegrierenden Wirkungen erwartet, die von den egoistisch-rationalen Individuen ausgeht, die auf dem wirtschaftlichen und politischen Markt ihren Eigennutz maximieren. Durch das gemeinsame Handeln in freiwilligen Assoziationen sollen nach dieser Vorstellung gemeinwohlorientierte Bürgertugenden entwickelt und stabilisiert werden. Mit diesem Verständnis bewegt man sich eindeutig in der republikanischen Tradition und im Kontext des republikanischen Modells der Demokratie. Dieses Argument der Förderung von Bürgertugenden durch Mitarbeit in freiwilligen Assoziationen ist auch von Putnam in Anschluß an Tocqueville gemacht worden, aber er hat es als eine empirisch testbare Hypothese formuliert und nicht als einen schon gesicherten Tatbestand oder lediglich als ein normatives Postulat.

Vor dem Hintergrund dieser Darstellung des Konzeptes der Zivilgesellschaft wird einsichtig, warum es ebenfalls nicht der geeignete theoretische Bezugspunkt unserer Analyse sein kann. Wenn wir uns auf den Gesichtspunkt der Mitarbeit in freiwilligen Assoziationen beschränken, dann wird nur ein bestimmtes Spektrum politischer Beteiligungsformen als normativ relevant erachtet. Wenn wir hingegen die weiteren normativen Zuschreibungen mit einbeziehen, dann ist die Zivilgesellschaft nichts anderes als ein bestimmtes normatives Modell einer demokratischen Gemeinschaft, das durch das republikanische Modell systematischer und vollständiger formuliert wird.

Eine Dimension der demokratischen Gemeinschaft ist bislang ausgeblendet worden. Diese betrifft die Frage, wie sich die Gemeinschaft in der subjektiven Wahrnehmung der Bürger als ein kollektives Subjekt mit einer Wir-Identität konstituiert. Am Anfang dieses Abschnittes wurde bereits festgestellt, daß im Bewußtsein der Bürger neben einer Grenzziehung nach außen auch eine Verbindung zu den anderen Mitgliedern der Gemeinschaft hergestellt werden muß. Das kann auf einer expressiven und auf einer substantiellen Grundlage erfolgen (Fuchs 1989). Eine Verbindung zu den anderen auf einer expressiven Grundlage besteht dann und in dem Maße, wie sich die Bürger mit dem Kollektiv gefühlsmäßig identifizieren. Eine Verbindung zu den anderen auf einer substantiellen Grundlage wird durch die Unterstellung gemeinsam geteilter Werte hergestellt. Erst diese Gemeinsamkeit kann eine kollektive Identität begründen. Die gemeinsamen Werte können sich inhaltlich unterscheiden, und zur Identifikation von Wertemustern in konkreten Ländern können wiederum die erörterten normativen Modelle der Demokratie herangezogen werden.

Eine in der Demokratieforschung noch ungeklärte Frage ist der Stellenwert einer expressiven Identifikation mit der Gemeinschaft einerseits und einer Gemeinsamkeit von Wertorientierungen andererseits für eine stabile und funktionierende Demokratie. Easton (1965) hat beides als eine Voraussetzung angesehen. Ähnlich argumentieren auch republikanische Theoretiker, die aber die weitergehende Annahme formulieren, daß nur gemeinsame ethi- 
sche Vorstellungen auch zu einer solchen Identifikation führen können. Nach liberaler Auffassung dürfen solche ethischen Vorstellungen aber lediglich die kollektive Identität von Teilgemeinschaften begründen. Die umfassende Gemeinschaft (community of communities) hingegen sollte gerade aufgrund der Pluralität dieser Gemeinschaft ethisch neutral sein und sich lediglich auf die Bindung an liberale Werte stützen. Diese Wertebindung soll die kollektive Identität der community of communities ausmachen und ausreichend sein, eine funktionierende Demokratie zu ermöglichen. Eine darüber hinausgehende expressive Identifikation mit der Gemeinschaft ist nicht vonnöten, außer diese beruht in der genannten Wertebindung. Letzteres im Begriff des Verfassungspatriotismus (Sternberger 1990; Habermas 1996) angelegt. Eine wertende Einstellung zu einer kognizierten nationalen Gemeinschaft ist als eine sehr abstrakte Wertorientierung, die sich einerseits mit konkreteren Werten verbinden und die andererseits für verschiedene Handlungskontexte spezifiziert werden kann, der Kulturebene des politischen Systems zugehörig. Die Kulturebene wird demzufolge vor allem von Werthaltungen zu drei allgemeinen Einstellungsobjekten konstituiert: der nationalen Gemeinschaft, der politischen Herrschaftsordnung und dem Ethos der Gemeinschaft. Diese drei Einstellungsobjekte werden in den Tabellen der empirischen Analyse wieder aufgegriffen.

\subsection{Die kulturellen Traditionen in den USA und Deutschland}

Im vorangehenden Abschnitt haben wir vier normative Typen einer demokratischen Gemeinschaft unterschieden (vgl. Schaubild 1). In der empirischen Analyse soll geklärt werden, welchen Typ die beiden Länder faktisch repräsentieren. Um sinnvolle Erwartungen an diese empirische Analyse richten zu können, nehmen wir eine kurze Darstellung der kulturellen Traditionen der USA und Deutschlands vor.

Mit der Berücksichtigung der kulturellen Tradition sind mehrere Annahmen verbunden. Erstens, daß es eine distinkte kulturelle Tradition, die sich langfristig herausgebildet hat, überhaupt gibt. Zweitens, daß diese kulturelle Tradition gravierende historische Ereignisse und Einschnitte mehr oder weniger überdauert hat. Auf dieses Problem kommen wir noch einmal zurück. Und drittens, daß sie auch einigermaßen valide beschrieben werden kann. Gegen alle drei Annahmen können durchaus Einwände formuliert werden. Diese wollen wir aus zwei Gründen aber weitgehend vernachlässigen. Zum einen besteht in maßgeblichen Studien über die kulturelle Tradition in den beiden Ländern eine erhebliche Übereinstimmung - zumindest was das Grundmuster anbetrifft. Zum anderen ist die Beschreibung der kulturellen Traditionen nicht der eigentliche Zweck unserer Analyse, sondern lediglich eine Heuristik zur Spezifikation von Hypothesen und zur Interpretation der empirischen Ergebnisse. 
Bei der Beschreibung der kulturellen Traditionen gehen wir von Amerika $^{3}$ aus und kontrastieren von daher Europa, obgleich Europa die ungleich längere Tradition aufweist und Amerika zumindest anfänglich ein - bestimmter - Ausdruck dieser Tradition gewesen ist. Das geschieht aus zwei Gründen. Zum einen liegen für Amerika eindrucksvolle Studien vor (McClosky und Zaller 1984; Lipset 1996). Diese stützen sich wiederum auf eine Vielzahl anderer Analysen, die seit Tocqueville durchgeführt wurden. Zum anderen ist Amerika aufgrund seines außerordentlichen Erfolges ein oder vielleicht sogar der exemplarische Fall einer funktionierenden und stabilen Demokratie und Marktwirtschaft.

Das amerikanische Wertesystem, das sich auf die Organisation einer guten Gesellschaft bezieht, bildete sich im 18. Jahrhundert heraus und bleibt in seinem ideologischen Kern bis heute wirksam. Es ist ein Resultat der amerikanischen Revolution und wurde von den protestantischen Sekten getragen, die aus Europa eingewandert sind (Hofstadter 1964; Lipset 1996). Bereits Tocqueville hatte festgestellt, daß die USA das religiöseste Land der Christenheit sei und das einzige Land, in dem Sekten und nicht Kirchen dominieren. Die protestantischen Sekten unterschieden sich von den europäischen Kirchen in mehrfacher Hinsicht. Erstens beruhten sie auf einem freiwilligen Engagement ihrer Mitglieder. Sie waren in keiner Weise mit staatlichen Strukturen verkoppelt und empfingen demgemäß auch keine staatliche Unterstützung. Zweitens war ihre interne Struktur nicht-hierarchisch. Die Beziehung der Mitglieder zu Gott war nicht durch Priester, Bischöfe etc. vermittelt, sondern eine persönliche und unmittelbare. Drittens pflegten diese Sekten einen moralischen Rigorismus, in den sie auch die ethischen Prinzipien der Selbstverantwortung und der Arbeits- und Leistungsorientierung einbezogen. Das alles trug nach Tocqueville zu der Herausbildung des Individualismus als dem hervorstechendsten Merkmal der amerikanischen Gesellschaft bei. Neben dem Ursprung der amerikanischen Gesellschaft als einer Auswanderer- und Siedlergesellschaft waren vor allem die protestantischen Sekten dafür verantwortlich, daß sich das amerikanische Wertesystem in einem Gegensatz zu Europa entwickelte, deren Gesellschaften einen aristokratischen und etatistischen Charakter aufwiesen, und deren Institutionen hierarchisch strukturiert waren. Dieser Gegensatz wurde durch die „American Revolution“ noch einmal verschärft (Lipset 1996: 31). Das Wertesystem, das sich schließlich herausgebildet hatte war der Liberalismus des 18. Jahrhunderts und dieser war ,essentially the rebellion ... against the monarchical and aristocratic state - against hereditary privilege, against restrictions on bargains. Its spirit was essentially anarchistic - the antithesis of Socialism. It was anti-State“ (H. G. Wells 1906: 72-76; zitiert nach Lipset 1996: 32).

Wir wollen im folgenden dieses amerikanische Wertesystem etwas genauer beschreiben. Es wird von McClosky und Zaller (1984) mit dem Begriff des „American ethos“ bezeichnet. Lipset (1996) verwendet dafür den Begriff des „American Creed“ und Ladd (1994) spricht einfach von der „American ideology“. Nach diesen Autoren wird es von zwei grundlegen-

3 In den meisten Studien werden Amerika und USA synonym verwendet. Dem schließen wir uns im folgenden an. 
den Werten dominiert und strukturiert: der Freiheit der einzelnen Bürger und der Gleichheit zwischen diesen Bürgern. Zwischen diesen beiden Werten wird im allgemeinen eine inhärente Spannung angenommen, die aber im „American ethos“ wenn nicht aufgelöst, so doch weitgehend reduziert wird. Zum einen existiert in dieser Ideologie keine Balance zwischen den beiden Werten, sondern die Freiheit der Individuen hat den eindeutigen Vorrang vor ihrer Gleichheit (McClosky und Zaller 1984: 18; Ladd 1994: 2; Lipset 1996: 20). Zum anderen wird die Gleichheit in Abgrenzung zu den aristokratischen Gesellschaften Europas vor allem als gleicher Wert aller Menschen begriffen. Dieser verwirklicht sich nicht als eine Gleichheit der Bedingungen oder gar der Resultate, sondern als eine Gleichheit der Chancen an dem Wettbewerb der Individuen auf den verschiedenen Märkten (Wirtschaft, Politik, Wissenschaft etc.) teilzunehmen und dort bestehen zu können (Lipset 1996: 32). In das konkrete Verständnis der Gleichheit und der Freiheit fließt ein anderes Element des amerikanischen Wertesystems ein, das vor allem von der Ethik der protestantischen Sekten geprägt wurde. Nach der Ideologie des ,asketischen Protestantismus“ (Weber 1988) sind die menschlichen Schicksale zwar göttlich prädestiniert, aber diese Schicksalsbestimmtheit zeigt sich im konkreten Leben an den Erfolgen, die die Individuen haben. Das führt zur Herausbildung einer individualistischen Leistungs- und Arbeitsethik. Diese soll in der Konkurrenz der Individuen auf den Märkten die angestrebten Erfolge bringen. Die aus den unterschiedlichen Fähigkeiten und Motivationen resultierenden Ungleichheiten in der Verteilung materieller und anderer Ressourcen können der Prädestinationslehre gemäß auch nicht als ungerecht betrachtet werden. Dieses ideologische Muster übt einen starken Druck auf die Individuen aus, ihre individuellen Freiheitsspielräume in möglichst große Anstrengungen zur Realisierung möglichst großer Erfolge zu investieren. Die beiden grundlegenden Werte - Freiheit und Gleichheit - gewinnen ihren spezifischen Gehalt im amerikanischen Wertesystem also durch ihre Verkoppelung mit der Leistungs- und Arbeitsethik, die Erfolge im Wettbewerb zwischen den Individuen auf den Märkten garantieren soll (McClosky und Zaller 1984: 114ff; Lipset 1996: 53). Diese verschiedenen Komponenten des „American ethos“ können zu dem Begriff des kompetitiven Individualismus zusammen gezogen werden.

Dieser Wertekern hat unmittelbare Auswirkungen auf die gesellschaftlichen Wertorientierungen, das heißt auf die grundlegenden Vorstellungen wie die wichtigsten gesellschaftlichen Systeme strukturiert sein sollten. Im Falle des ökonomischen Systems entspringt daraus eine möglichst uneingeschränkte Marktwirtschaft und im Falle des politischen Systems zunächst einmal eine Demokratie als Herrschaftsordnung. Die aus dem kompetitiven Individualismus erfolgende Wertespezifikation für den Bereich der Politik geht aber noch erheblich weiter. Sie führt zu dem Postulat eines minimalen und schwachen Staates. Lipset (1996) betont in seiner Studie immer wieder, daß Amerika die Demokratie ist, in der eine antistaatliche Haltung am ausgeprägtesten ist. Mit der Anti-Staatlichkeit verbunden ist ein AntiPaternalismus (Shell 1989), der zugleich impliziert, daß nicht der Staat, sondern die Indivi- 
duen für ihre Lebensgestaltung verantwortlich sein sollen. Diese Selbstverantwortlichkeit schließt Solidarität nicht völlig aus, aber sie konkretisiert sich als freiwillige Unterstützung von unverschuldet in Not geratenen.

Vor allem dann, wenn sich eine Gemeinschaft in ausdrücklichen Veranstaltungen ihr politisches System selber schafft, wie das in Amerika der Fall war, kann dieses System als eine selektive Implementation kultureller Werte auf der Strukturebene - und das heißt durch die Verfassung - begriffen werden. In der amerikanischen Verfassung wurde durch verschiedene institutionelle Vorkehrungen versucht, einen minimalen und schwachen Staat zu konstituieren. Nettl (1968) spricht deshalb von einer „relative statelessness“. Die Begrenzung der Staatsmacht erfolgt durch das „divided government“ (Lipset 1996: 39) zwischen Präsident und Kongreß, den beiden Häusern des Kongresses und natürlich auch durch die starke föderale Struktur. Eine weitere institutionelle Vorkehrung besteht in dem vergleichsweise hohen Stellenwert der Wahlen. Im Unterschied zu Europa finden sehr viel häufiger Wahlen statt und zudem werden auf lokaler Ebene auch das Führungspersonal der Justiz und der Polizei von den Bürgern gewählt. In Europa werden diese entweder ernannt oder über professionelle Karrieren rekrutiert. Lipset (1996: 42) bezeichnet den direkten Einfluß, den die Bürger auf diese Weise auf die Entscheidungsprozesse der Politie gewinnen als „populism“ und sieht diesen als ein weiteres Element des „American Creed“ an.

Das europäische Wertesystem verhält sich vor allem nach Lipset (1996), aber auch nach McClosky und Zaller (1984), Münch (1986) und Shell (1989) in entscheidenden Gesichtspunkten antithetisch zum amerikanischen. Der prägende Einfluß erfolgte durch die hierarchische Struktur der europäischen Gesellschaft (aristokratisch und monarchisch), und ihrer Institutionen (Kirche und Staat), die sich seit dem beginnenden Mittelalter herausgebildet hatte. Letztlich auf dieser Grundlage entwickelte sich im 19. Jahrhundert ein ,conservative Toryism“ (Lipset 1996), der für die weitere Geschichte der europäischen Gesellschaften wichtige Weichen stellte. Dieser enthielt die Überzeugung, daß gesellschaftliche Probleme vor allem durch einen aristokratisch geführten Staat gelöst werden sollten. Die soziale Stellung der europäischen Aristokratie basierte auf ihrem Landbesitz und in Folge dieser materiellen Basis wies die Aristokratie eine starke anti-kapitalistische und anti-marktwirtschaftliche Gesinnung auf. Nach Lipset (1996) waren die prominentesten Vertreter dieses „,conservative Toryism“ Disraeli in Großbritannien und Bismarck in Deutschland. Zu den zu lösenden gesellschaftlichen Problemen gehörten im 19. Jahrhundert vor allem die desolate Situation der unteren Klassen. Disraeli und Bismarck favorisierten zur Verbesserung ihrer Lage staatliche Lösungen und leiteten damit den Beginn der Herausbildung der europäischen Wohlfahrtsstaaten ein. Die Motive dieser wohlfahrtsstaatlichen Politik waren - neben dem materiellen Interesse der Sicherung der Privilegien der eigenen Klasse - die Werte der „noblesse oblige“ (Lipset 1996: 31). Bei derartig paternalistischen und etatistischen Vorstellungen konnten die Werte der Selbstverantwortung der Individuen und der Lösung 
gesellschaftlicher Probleme durch den Wettbewerb der Individuen auf freien Märkten naturgemäß nur eine periphere Rolle spielen.

Die Fragestellung der Studie von Lipset bezieht sich auf die Erfassung des amerikanischen Wertesystems. Um den American Exceptionalism herauszuarbeiten, verwendet er Europa als Kontrastfolie. Durch die dabei vorgenommenen Generalisierungen werden Großbritannien und Deutschland weitgehend als gleichartige Fälle Europas genommen und die zwischen ihnen bestehenden Unterschiede vernachlässigt. Diese Unterschiede sind nach verbreiteter Auffassung allerdings nicht unerheblich und werden häufig als Erklärung dafür herangezogen, daß Deutschland und Großbritannien in der ersten Hälfte des 20. Jahrhunderts eine so unterschiedliche Entwicklung genommen haben.

Die Besonderheit Deutschlands gegenüber anderen westlichen Gesellschaften wurde in den fünfziger Jahren von Plessner (1959) und in den sechziger Jahren von Dahrendorf (1965) in einflußreichen Studien beschrieben, und in einer jüngeren Arbeit nahm sich Münch (1986) dieses Themas an. Sie beruhte vor allem in dem, was als eine verzögerte Modernisierung Deutschlands bezeichnet werden kann. In Deutschland dauerte die Vorherrschaft des Absolutismus länger an als zum Beispiel in Frankreich und Großbritannien. Die Revolution des Bürgertums von 1848 scheiterte und führte zu einer Restauration des alten Regimes. Die Industrialisierung setzte verspätet ein und wurde vor allem durch den Staat und den diesen dominierenden aristokratischen Eliten vorangetrieben, damit sich Deutschland in der Konkurrenz der europäischen Großmächte behaupten konnte (Dahrendorf 1965). Unter diesen Bedingungen konnte sich kein selbstbewußtes Bürgertum mit einer individualistischen Ethik herausbilden (Plessner 1959), das die gesellschaftliche Modernisierung trug und individualistische Vorstellungen von Freiheit und Gleichheit entwickelte, wie das vor allem in Amerika und in eingeschränkterem Ausmaß auch in Großbritannien der Fall war. Freiheit war weniger die Freiheit von Marktteilnehmern, sondern eher die Freiheit von vernunftbegabten Kulturpersonen (Krieger 1957), und Gleichheit war weniger die individuelle Chancengleichheit im Wettbewerb auf den Märkten, sondern eher die Gleichheit von Ständen und Klassen. Dahrendorf (1965) stellt fest, daß die deutsche Industrialisierung im Unterschied zu den angelsächsischen Ländern den Liberalismus nicht entfaltete, sondern ihn eliminierte. Münch (1986: 699) kommt zu der Schlußfolgerung: „In Deutschland ist die Dynamik der gesellschaftlichen Entwicklung von Anfang an und bis heute vom Staat bestimmt worden.“ $\mathrm{Zu}$ den Aufgaben des Staates gehörten spätestens seit Bismarck sozialpolitische Maßnahmen und Einrichtungen zur Verbesserung der Lebensverhältnisse der unteren Klassen. Diese wurden - wie bereits festgestellt - von dem Selbsterhaltungsinteresse der aristokratischen Eliten und der Ethik der ,noblesse oblige“ bestimmt. Dahrendorf (1965) bezeichnet den deutschen Staat in dieser Zeit unter anderem deshalb als einen autoritären Wohlfahrtsstaat.

Diese ausgeprägte Staatsorientierung wurde von dem lutheranischen Protestantismus gefördert und stabilisiert. $\mathrm{Zu}$ dem lutheranischen Ethos gehörte die Gehorsamspflicht der Untertanen gegenüber der Obrigkeit und die Erfüllung eines Arbeits- und Pflichtethos 
(Münch 1986: 709ff). Im Hinblick auf die Arbeitsethik scheinen sich Berührungspunkte zu den protestantischen Sekten Amerikas zu ergeben. Allerdings ist die Grundlage dieser Ethik in Europa eher die Idee der Pflichterfüllung und nicht der „empirische“ Beleg vor sich und den anderen, daß man zu den Auserwählten Gottes gehört. Dieser Gedanke des Auserwähltseins bedeutet auch, daß man sich hinsichtlich des durch Arbeit erzielten Erfolges von vielen oder sogar von den meisten anderen unterscheiden muß, denn sonst hätte der Gedanke des Auserwähltseins keinen Sinn. Diese ausdrückliche Differenz zu den anderen ist bei einer pflichtbegründeten Arbeitsethik nicht notwendig oder vielleicht sogar kontraproduktiv. Zudem ist der lutheranische Arbeitsethos nicht mit einer ,selbstbewußten und aktiv gestaltenden Teilnahme am beruflichen und politischen Leben“ (Münch 1986: 711) verbunden, wie das bei den protestantischen Sekten und ihrem calvinistischen Ethos der Fall war. Der lutheranische Obrigkeitsglaube und sein Arbeitsethos war ein ermöglichender und verstärkender Faktor der preußischen Staatsidee, die den Staat über die Gesellschaft stellte und die von den Beamten und Soldaten, die die wichtigsten Träger des Staates waren, eine möglichst bedingungslose Disziplin verlangten (Münch 1986: 712).

Die verschiedenen Elemente des amerikanischen Wertesystems wurden in dem Begriff des kompetitiven Individualismus zusammengefaßt. Für eine entsprechende Zusammenfassung der erläuterten Elemente des europäischen und deutschen Wertesystems scheint uns der Begriff des solidarischen Etatismus angemessen zu sein.

Bevor wir auf der Grundlage der geschilderten kulturellen Traditionen von Amerika und Deutschland zu Annahmen über die gegenwärtige Situation und zu Erwartungen an die empirische Analyse kommen, ist die Erörterung eines Problems unabdingbar, das am Anfang dieses Abschnitts bereits erwähnt wurde. Die geschilderte kulturelle Tradition von Amerika einerseits und Europa bzw. Deutschland andererseits bezieht sich bestenfalls auf die Zeit bis zum 1. Weltkrieg. Die offene Frage ist, inwieweit sie die gravierenden Ereignisse und gesellschaftlichen Wandlungen des 20. Jahrhunderts überdauert haben. Diese Frage greift Lipset (1996: 22) ausdrücklich für Amerika auf und er konstatiert: „American values were modified sharply by forces stemming from the Great Depression and World War II. These led to a much greater reliance on the state and acceptance of welfare and planning policies, the growth of trade unions and class divisions in voting". Vor allem die sozialen Probleme, die sich in den zwanziger und dreißiger Jahren stellten, änderten die amerikanische Politik grundlegend. Es kam zu einer Europäisierung bzw. zu einem ,socialdemocratic tinge“ (Hofstadter 1972: 37). Diese Europäisierung verlief nicht nur in einem Gegensatz zum traditionellen amerikanischen Wertesystem, sondern sie knüpfte an ein Merkmal an, das McClosky und Zaller (1984) als die demokratische Komponente des „American ethos“ begreifen. Dieses besteht in dem gleichen Wert aller Bürger und der faktischen Chancengleichheit bei der Gestaltung der gesellschaftlichen Verhältnisse. Diese Werte wurden durch die eklatante gesellschaftliche Ungleichheit in der Verteilung der materiellen Ressourcen, durch die Verelendung vieler Bürger und durch die Wahrnehmung, daß die Gesellschaft von 
wenigen privilegierten Gruppen bestimmt wurde, in Frage gestellt (McClosky und Zaller 1984: 264). Die gesellschaftliche Folge dieser Konstellation war die Entwicklung einer neuen Konfliktstruktur, die sich analog zu Europa an dem Gegensatz von Kapital und Arbeit festmachte. Die Folge auf der institutionell-politischen Ebene war die Herausbildung eines Wohlfahrtsstaates. Diese Europäisierung der amerikanischen Politik konnte den „American ethos“ nicht unangetastet lassen und führte zu einer Aufweichung extrem individualistischer und anti-staatlicher Werthaltungen (McClosky und Zaller 1984: 266ff). Lipset streicht aber heraus, daß die Annäherung Amerikas an Europa nur eine relative gewesen sei. Die anhaltende ökonomische Prosperität nach dem Zweiten Weltkrieg führte zudem zu einer Revitalisierung der „classical liberal ideology“ mit ihrem Mißtrauen gegenüber einem starken Staat und dem Vorbehalt gegenüber sozialstaatlichen Politiken (Lipset 1996: 36). Er verdichtet diese Relativierung zu der folgenden Schlußfolgerung für die heutige Situation: „America remain more individualistic, meritocratic-oriented, and anti-statist than other peoples elsewhere“ (Lipset 1996: 38).

Während für Amerika also eine gewisse Kontinuität der kulturellen Tradition angenommen werden kann, ist das für Deutschland viel fraglicher. Die gesellschaftliche Modernisierung erfolgte im Vergleich zu den anderen westlichen Ländern zwar verzögert, aber dann in einem derartigen Tempo und Ausmaß, daß Deutschland heute zu den weltweit modernsten Gesellschaften gehört. Zudem haben die beiden verlorenen Weltkriege mit ihren Begleiterscheinungen und Folgewirkungen die deutsche Gesellschaft in einem erheblichen Ausmaß verändert. Die Konsequenzen für die Wertorientierungen der Deutschen im Bereich der Politik sind empirisch vielfach dokumentiert worden (Barnes, Kaase u. a. 1979; Conradt 1980; Baker, Dalton und Hildebrandt 1981; Fuchs 1989; Jennings, van Deth u. a. 1990). Nach diesen Studien hat sich das Wertesystem in Deutschland dem der anderen westlichen Länder angeglichen und sich im Sinne von Almond und Verba (1963) von einer ,subject culture“ zu einer „civic culture“ transformiert. Das impliziert unter anderem, daß die Demokratie als Herrschaftsordnung nahezu konsensuell akzeptiert wird, daß die Demokratie des eigenen Landes auf eine hohe Zustimmung stößt und daß die Bereitschaft der Bürger, sich politisch zu beteiligen, relativ hoch ist.

Dennoch können auch im Falle Deutschlands Kontinuitäten in der kulturellen Tradition festgestellt werden. Diese betreffen zum einen den lutheranischen Arbeitsethos, der von vielen Beobachtern als einer der Gründe für den außerordentlichen ökonomischen Aufschwung der Bundesrepublik nach dem Zweiten Weltkrieg angesehen wird. Diese betreffen zum anderen und vor allem die ausgeprägte Staatsorientierung und die entsprechende Erwartung, daß der Staat für das Lebensschicksal der einzelnen Bürger eine maßgebliche Verantwortung trägt. Das führte dazu, daß sich die Bundesrepublik zu einem ausgeprägten Wohlfahrtsstaat entwickelte, der neben der ökonomischen Prosperität einer der wichtigsten Faktoren für die Stabilität und Legitimität der Demokratie war (Roller 1992). Die Etablierung des Wohlfahrtsstaates erfolgte auf der Ebene der alltäglichen politischen Auseinander- 
setzungen und innerhalb des Rahmens einer liberalen Verfassung, und beides entspricht den Kriterien des liberalen (sozialdemokratischen) Modells der Demokratie.

Durch den Zerfall der Arbeiterbewegung und durch die Existenz des Wohlfahrtsstaates veränderte sich in den europäischen Staaten und somit auch in Deutschland der Charakter der gesellschaftlichen Solidarität. Diese verwirklicht sich nicht mehr als eine unmittelbare und lebensweltliche Solidarität in den alltäglichen Interaktionen der Individuen, wie das unter anderem in den Milieus der Arbeiterbewegung der Fall war - und in anderer Weise und anders motiviert in den lokalen Gemeinschaften Amerikas - sondern in staatlichen Maßnahmen zur Herstellung sozialer Gerechtigkeit. Die konkrete Solidarität unter den Individuen transformierte sich also in eine abstrakte Solidarität, die durch den Staat vermittelt ist und durch ihn umgesetzt wird.

Anders als im westlichen Teil Deutschlands verlief die Entwicklung in der DDR. Der Staatssozialismus in der DDR knüpfte unmittelbar an die etatistischen und paternalistischen Wertorientierungen an, die in der kulturellen Tradition Deutschlands angelegt waren. Die DDR war im Unterschied zur Bundesrepublik ein umfassender Wohlfahrtsstaat, der nahezu alle Lebensbereiche der Bürger einschloß und der durch die Verfassung der DDR garantiert wurde (Roller 1997). Mit diesem sozialistischen Wohlfahrtsstaat sind im Vergleich zu den westlichen Ländern erheblich egalitärere Wertvorstellungen verbunden, und bei dem Spannungsverhältnis von Freiheit und Gleichheit hat - im Gegensatz zum liberalen Demokratiemodell - die Gleichheit den relativen Vorrang. In Abwandlung der Bezeichnung des deutschen Staates des Kaiserreiches als einem autoritären Wohlfahrtsstaat (Dahrendorf 1965) kann man den Staat der DDR als einen autokratischen Wohlfahrtsstaat bezeichnen.

Dieses Merkmal der Autokratie wollte die Mehrheit der Bürger der früheren DDR nicht mehr hinnehmen, wie der Zusammenbruch des DDR-Systems am Ende der achtziger Jahre zeigte. Die Bürger der DDR wollten und wollen eine Demokratie als Herrschaftsordnung. Dieses gründet in ihren Erfahrungen mit dem repressiven Charakter des DDR-Systems und in dem Vergleich mit den erfolgreicheren westlichen Gesellschaften. Insofern können die Bürger der neuen Bundesländer als eine demokratische Gemeinschaft begriffen werden, die in dieser Hinsicht eine Einheit mit den Bürgern der alten Bundesländer bilden. Wir gehen allerdings davon aus, daß die Sozialisation in unterschiedlichen Gesellschaftsordnungen in anderen Hinsichten erhebliche Differenzen bewirkt hat. Das ist theoretisch mehrfach begründet (Lepsius 1995; Wiesenthal 1996; Schluchter 1996) und empirisch umfassend belegt worden (Fuchs 1997a, 1997b; Gabriel 1997; Roller 1997; Rohrschneider 1999). Der wichtigste Unterschied liegt in den vergleichsweise starken Erwartungen der Bürger der neuen Bundesländer an den Staat und einer damit verbundenen unterentwickelten Selbstverantwortungsethik. Der Staat ist aus der Sicht dieser Bürger für die Absicherung der primären Lebensrisiken, für die Verwirklichung gemeinschaftlicher (abstrakter) Solidarität sowie für soziale Gerechtigkeit zuständig, und diese Zuständigkeit sollte ihrer Auffassung nach auch in die Verfassung aufgenommen werden (Fuchs 1997a). Dieses „Erbe des Sozialis- 
mus“ führt dazu, daß die Bürger der neuen Bundesländer zwar eine Demokratie als Herrschaftsordnung präferieren, aber im Unterschied zu den Bürgern der alten Bundesländer nicht die Demokratie, die im vereinigten Deutschland implementiert ist und die dem normativen Modell der liberalen Demokratie entspricht (Fuchs 1997a, 1997b).

Zur Vorbereitung der empirischen Klärung, welche demokratische Gemeinschaft beide Länder heute faktisch repräsentieren, wollen wir eine Vereinfachung der erörterten Komplexität der kulturellen Traditionen von Amerika und Deutschland vornehmen. $\mathrm{Zu}$ diesem Zweck beziehen wir diese kulturellen Traditionen auf die in Schaubild 1 dargestellte Typologie demokratischer Gemeinschaften zurück. Nach den beiden Dimensionen der Typologie - „Verantwortung des Individuums für eigenes Lebensschicksal“ und „Verhältnis der Individuen zueinander" - muß Amerika aufgrund der individualistischen, anti-staatlichen und meritokratischen Orientierungen seiner Bürger zweifellos als eine demokratisch-libertäre Gemeinschaft eingestuft werden. Wenn wir allerdings noch weitere Merkmale berücksichtigen, dann bekommt die demokratische Gemeinschaft Amerikas einige kräftige republikanische Elemente. Das drückt sich vor allem auf der Ebene der lokalen Einheiten des politischen Systems aus. Dort gibt es eine verbreitete Teilnahme an freiwilligen Organisationen, die bereits Tocqueville festgestellt hat und die nach Lipset (1996) noch heute im Vergleich zu anderen Ländern des Westens überdurchschnittlich hoch ist. Auf lokaler Ebene läßt sich auch eine freiwillige Solidarität feststellen, die sich zum Beispiel in dem hohen Spendenaufkommen für soziale und andere kommunale Angelegenheiten ausdrückt (Lipset 1996). Ein weiteres republikanisches Element besteht in dem moralischen Rigorismus in ethischen Fragen, der direkt auf die Tradition der protestantischen Sekten zurückgeht. Dieser bezieht sich im wesentlichen zwar auf ,private“ Fragen der Familie, Ehe und Sexualität, aber die entsprechenden ethischen Vorstellungen werden auch in den „öffentlichen“ Bereich der Politik hineingetragen, wie die vielfältigen Skandale von Politikern und wie vor allem die erbitterten Auseinandersetzungen über die Abtreibung deutlich machen (Ferree, Gamson, Gerhards und Rucht 2000). Dennoch muß die demokratische Gemeinschaft der USA - vor allem auf der nationalen Ebene - aufgrund ihres stark entwickelten Individualismus und dem damit verbundenen eindeutigen Primat der individuellen Freiheit vor der Gleichheit dominant als eine libertäre betrachtet werden.

Trotz der autoritären und autokratischen Tradition in der Geschichte Deutschlands können heute die Bürger aus beiden Teilen Deutschlands als demokratische Gemeinschaften gelten. Die unterschiedlichen Gesellschaftsordnungen, in der sie nach dem Zweiten Weltkrieg über mehrere Jahrzehnte hinweg gelebt haben, haben die langfristigen kulturellen Traditionen Deutschlands aber in unterschiedlicher Weise aufgegriffen und modifiziert und führten zur Herausbildung divergenter Werteorientierungen in anderen Hinsichten. Diese Divergenz bezieht sich vor allem auf das Verhältnis der Bürger zum Staat sowie der Bürger untereinander. Der Staatssozialismus der DDR setzte die etatistische und paternalistische Tradition der Deutschen fort und verstärkte gleichzeitig eine (abstrakte) Solidaritätsbereit- 
schaft. Demgegenüber haben die Bürger der alten Bundesländer ihre Erfahrungen mit einer „freiheitlich-demokratischen Grundordnung“ und mit einer funktionierenden Marktwirtschaft gemacht, und diese Erfahrungen führten - neben den grundlegenden gesellschaftlichen Modernisierungsprozessen - zu einer verstärkten Herausbildung individualistischer Werthaltungen. Bezogen auf die Typologie demokratischer Gemeinschaften müssen die Bürger der alten Bundesländer demzufolge einer demokratisch-liberalen und die Bürger der neuen Bundesländer einer demokratisch-sozialistischen Gemeinschaft zugeordnet werden.

In der nachfolgenden empirischen Analyse soll unter anderem überprüft werden, inwieweit diese Klassifikation der demokratischen Gemeinschaften in den USA und in den beiden Teilen Deutschlands empirisch zutrifft. Zu diesem Zweck nehmen wir im ersten Abschnitt dieser empirischen Analyse eine Präzisierung der Merkmale der demokratischen Gemeinschaft und ihrer unterschiedlichen Typen in Form von Hypothesen vor, die die Interpretation der empirischen Befunde erleichtern soll.

\section{Empirische Analyse}

\subsection{Hypothesen über demokratische Gemeinschaften}

Der erste Satz von Hypothesen spezifiziert diejenigen Merkmale, die empirisch vorliegen müssen, damit eine gesellschaftliche Gemeinschaft faktisch als eine demokratische bezeichnet werden kann, in Je-Desto-Formulierungen. Dabei wird wiederum zwischen den Ebenen der Kultur, der Struktur und des Prozesses unterschieden. Wir beginnen mit der Kulturebene. Die erste Hypothese bezieht sich auf die politische Herrschaftsordnung und die zweite auf die anderen Mitglieder der gesellschaftlichen Gemeinschaft:

H1: Je stärker die Unterstützung einer Demokratie und je stärker die Ablehnung einer Autokratie, desto mehr entspricht die gesellschaftliche Gemeinschaft einer demokratischen Gemeinschaft.

H2: Je stärker die Anerkennung der anderen Mitglieder der Gemeinschaft als Freie und

Gleiche, desto mehr entspricht die gesellschaftliche Gemeinschaft einer demokratischen Gemeinschaft.

Mit der Je-desto-Formulierung ist zugleich ein idealer Zustand definiert: Wenn alle Bürger einer Gemeinschaft die Demokratie unterstützen, die Autokratie ablehnen und die Anderen als Freie und Gleiche anerkennen, dann liegt eine ideale demokratische Gemeinschaft vor. Die Definition dieses idealen Zutandes erlaubt eine empirische Bestimmung der Nähe und Ferne konkreter Gemeinschaften zu dieser Idealität.

Auf der Strukturebene ist die Formulierung einer Hypothese problematischer. Es wurde bereits erörtert, daß die Unterstützung und die Ablehnung der Demokratie des eigenen Landes auf unterschiedlichen Gründen beruhen kann (vgl. Abschnitt 2.1). Wenn zum Beispiel 
die Bürger eines fiktiven Landes ihr demokratisches System nur deshalb unterstützen, weil es für Ruhe und Ordnung sorgt oder weil es materielle Gratifikationen bereitstellt, dann qualifiziert das diese Bürger nicht als eine demokratische Gemeinschaft. Diese Kriterien könnten auch durch andere politische Systeme erfüllt werden und vielleicht sogar noch besser. In jedem Falle ist nach Maßgabe dieser Leistungskriterien die Demokratie ein kontingentes politisches System und steht grundsätzlich zur Disposition. Wir müssen in der Hypothese deshalb die Einstellung zur Demokratie des eigenen Landes mit den Gründen für diese Einstellung verkoppeln:

H3: Je stärker die Unterstützung oder die Ablehnung der Demokratie des eigenen Landes auf die Anwendung demokratischer Normen zurückgeht, desto mehr entspricht die gesellschaftliche Gemeinschaft einer demokratischen Gemeinschaft.

Eine auf demokratischen Normen beruhende Unterstützung der Herrschaftsordnung eines Landes kann mit dem Begriff der Legitimität gekennzeichnet werden (Fuchs 1989). Durch die Verkoppelung einer affektiven Bewertung mit den Gründen dieser Bewertung ist die Messung dieser Einstellung aber nicht einfacher geworden. Zudem kann gefragt werden, ob zur Identifikation einer demokratischen Gemeinschaft die grundlegende Akzeptanz der Demokratie als Herrschaftsordnung nicht ausreicht (vgl. Hypothese H1). Die Hypothese H3 ist unseres Erachtens aber deshalb sinnvoll, weil die geäußerte Akzeptanz eines Wertes auch unverbindlich sein kann. Folgenreich sind Wertebindungen erst dann, wenn sie auf reale Phänomene und auf reales Verhalten bezogen werden und hier eine praktische Wirksamkeit entfalten.

Die Prozeßebene wird durch die politischen Akteure und ihren Handlungen konstituiert. Wir können auf dieser Ebene zwei Klassen von Akteuren unterscheiden: die professionellen Akteure des politischen Entscheidungssystems (Politie) und die normalen Staatsbürger. Die normativen Erwartungen einer demokratischen Gemeinschaft an die Akteure beider Klassen bestehen vor allem in der Befolgung der Rechtsnormen, die durch die demokratischen Verfahren gesetzt und legitimiert worden sind. Unter diesen Rechtsnormen hat das Verbot von Gewalt als politisches Mittel einen hervorgehobenen Stellenwert, weil es den Kern jeder gelingenden Integration einer Gemeinschaft tangiert (Fuchs 1999). Die entsprechenden Hypothesen lauten folgendermaßen:

H4: Je weniger Gewalt als politisches Mittel eingesetzt wird, desto mehr entspricht die gesellschaftliche Gemeinschaft einer demokratischen Gemeinschaft.

H5: Je stärker die Befolgung der Legalitätsnormen im politischen Handeln, desto mehr entspricht die gesellschaftliche Gemeinschaft einer demokratischen Gemeinschaft.

Eine weitere - und für eine demokratische Gemeinschaft wesentliche - normative Erwartung für die Prozeßebene ist die Beteiligung der Bürger an der Politik. Dafür stehen den Bürgern ein ganzes Spektrum von Handlungsformen zur Verfügung. Ihr jeweiliger Stellen- 
wert wird aber je nach normativer Demokratietheorie sehr unterschiedlich eingeschätzt. Wir können deshalb ohne stärkere normative Prämissen lediglich für die Wahlbeteiligung eine Je-desto-Hypothese formulieren:

H6: Je stärker die Beteiligung der Bürger an den nationalen Wahlen, desto mehr entspricht die gesellschaftliche Gemeinschaft einer demokratischen Gemeinschaft.

Wie im Abschnitt 2.1 bereits angesprochen worden ist, ist auch diese Hypothese nicht ganz unproblematisch, da es für eine funktionierende Demokratie nicht unbedingt notwendig ist, daß sich möglichst alle Bürger immer an den jeweiligen Wahlen beteiligen, sondern nur ein „gewisses Minimum“. Wie groß dieses Minimum sein muß, ist allerdings theoretisch nicht angebbar.

Der nächste Satz von Hypothesen greift die Differenzierung der demokratischen Gemeinschaft in die bereits dargestellten unterschiedlichen Typen auf (s. Schaubild 1). Zur Spezifikation dieser Hypothesen werden die beiden Dimensionen der Typologie - „Verantwortung der Individuen für eigenes Lebensschicksal“ und „Verhältnis der Individuen zueinander" - herangezogen:

H7: Je stärker die Selbstverantwortung und je stärker die Konkurrenzorientierung, desto mehr entspricht die demokratische Gemeinschaft einer libertären Gemeinschaft.

H8: Je stärker die Staatsverantwortung und je stärker die abstrakte Solidaritätsorientierung, desto mehr entspricht die demokratische Gemeinschaft einer sozialistischen Gemeinschaft.

H9: Je stärker die Staatsverantwortung für die Chancengleichheit der Individuen und je stärker die Konkurrenzorientierung, desto mehr entspricht die demokratische Gemeinschaft einer liberalen Gemeinschaft.

H10: Je stärker die Selbstverantwortung und je stärker die konkrete Solidaritätsorientierung, desto mehr entspricht die demokratische Gemeinschaft einer republikanischen Gemeinschaft.

Im Unterschied zur demokratischen Gemeinschaft, für die Hypothesen auf allen drei Ebenen des politischen Systems formuliert werden, beziehen sich diese Hypothesen lediglich auf die Kulturebene. Und um noch einmal festzuhalten: unter abstrakter Solidarität wird die staatlich vermittelte und durch den Einsatz staatlicher Zwangsmittel hergestellte Solidarität verstanden und unter konkreter Solidarität die freiwillige Solidarität der Mitglieder einer lokalen Gemeinschaft. Die Herstellung der Chancengleichheit erfolgt zumindest in dem liberalen Modell von Rawls (1993) durch die möglichst gleiche Verteilung von Grundgütern, und diese Gleichheit hat im Zweifelsfalle hinter der Freiheit der Individuen zurückzustehen. 


\subsection{Dimensionen der Einstellungen der demokratischen Gemeinschaften}

\subsubsection{Darstellung der Indikatoren}

Die systematische empirische Analyse berücksichtigt lediglich die Erhebungen des World Values Survey, die zwischen 1995 und 1997 stattfanden und auf repräsentativen Bevölkerungsstichproben beruhten. Nur für einige Behauptungen werden zusätzliche Daten herangezogen. Da die Fragebögen des World Values Survey weitgehend identisch waren ist die Vergleichbarkeit zwischen den Ländern gewährleistet. Darüber hinaus enthielten die Fragebögen relativ viele Indikatoren, die zur Erfassung der Einstellungen der demokratischen Gemeinschaft geeignet sind. Allerdings können auf der Grundlage des World Values Survey nicht alle Einstellungen erfaßt werden, die im theoretischen Teil unserer Analyse diskutiert wurden und manche nur unvollkommen. Die in der Studie enthaltenen Indikatoren sind den Tabellen 1.1 bis 1.3 und 2.1 bis $2.3 \mathrm{zu}$ entnehmen. In diesen Tabellen sind die Ergebnisse einer dimensionalen Analyse (Faktorenanalyse) der Indikatoren verzeichnet. Die Interpretation dieser Ergebnisse wollen wir vorerst zurückstellen und mit der Erläuterung der Indikatoren beginnen. Dazu reicht der Bezug auf die Tabellen für die USA (Tabellen 1.1 und 2.1) aus, da die entsprechenden Tabellen für die beiden Teile Deutschlands nach demselben Muster aufgebaut sind.

Die einzelnen Indikatoren sind den theoretischen Konstrukten zugeordnet, die sie messen sollen. Die Anordnung der Konstrukte und Indikatoren in der Tabelle 1.1 folgt der Differenzierung des demokratischen Systems in die Ebenen der Kultur, der Struktur und des Prozesses. Diese Ebenen werden in der Tabelle optisch durch gestrichelte Linien abgegrenzt.

Die Kulturebene besteht aus drei Einstellungsbereichen: erstens der ,nationalen Gemeinschaft“(I), zweitens der ,politischen Herrschaftsordnung“ (II) und drittens dem „Ethos der Gemeinschaft“ (III). Die „,nationale Gemeinschaft“ enthält lediglich eine Einstellung und zwar die „Identifikation mit der nationalen Gemeinschaft“(1). Diese wird mit zwei Indikatoren erfaßt, und beide stellen eine expressive Orientierung dar. Während der Indikator über den „Stolz darauf, Amerikaner (bzw. Deutscher) zu sein“ (1.1) diese expressive Orientierung direkt messen soll, drückt die „Bereitschaft, für das eigene Land zu kämpfen“ (1.2) eine äußerst anspruchsvolle Konsequenz dieser Identifikation mit der nationalen Gemeinschaft aus. Da diese Indikatoren lediglich eine expressive Einstellung erfassen, ist auf ihrer Grundlage alleine auch nicht zu klären, ob das in einer konkreten Gemeinschaft auffindbare Identifikationsausmaß mit einer demokratischen Gemeinschaft verträglich ist oder nicht. 
Tabelle 1.1: Dimensionen der Einstellungen der demokratischen Gemeinschaft in den USA (Faktorenanalyse ${ }^{a}$ )

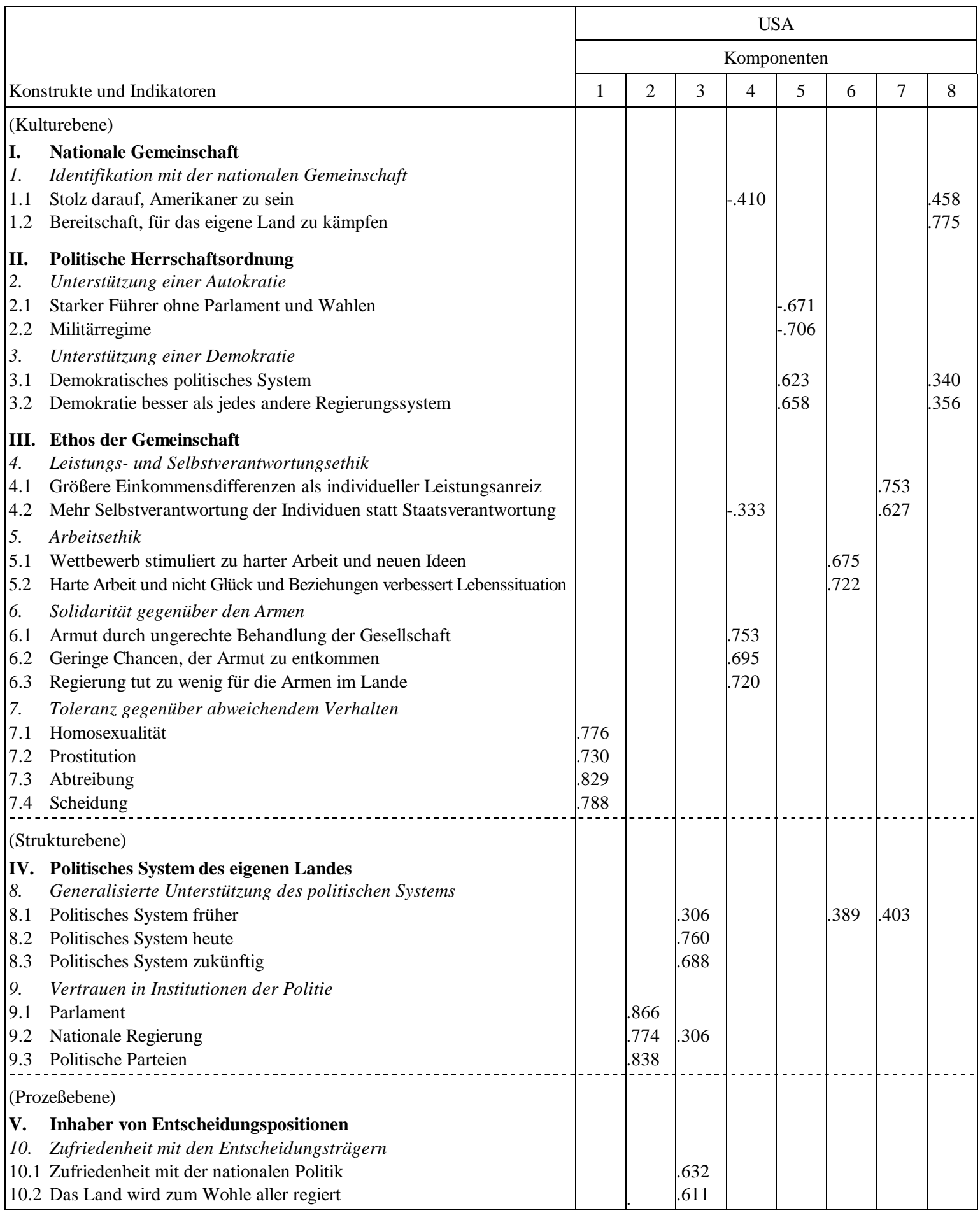

a Extraktionsmethode: Hauptkomponentenanalyse; Rotationsmethode: Varimax 
Tabelle 1.2: Dimensionen der Einstellungen der demokratischen Gemeinschaft in Deutschland, alte Bundesländer (Faktorenanalyse ${ }^{a}$ )

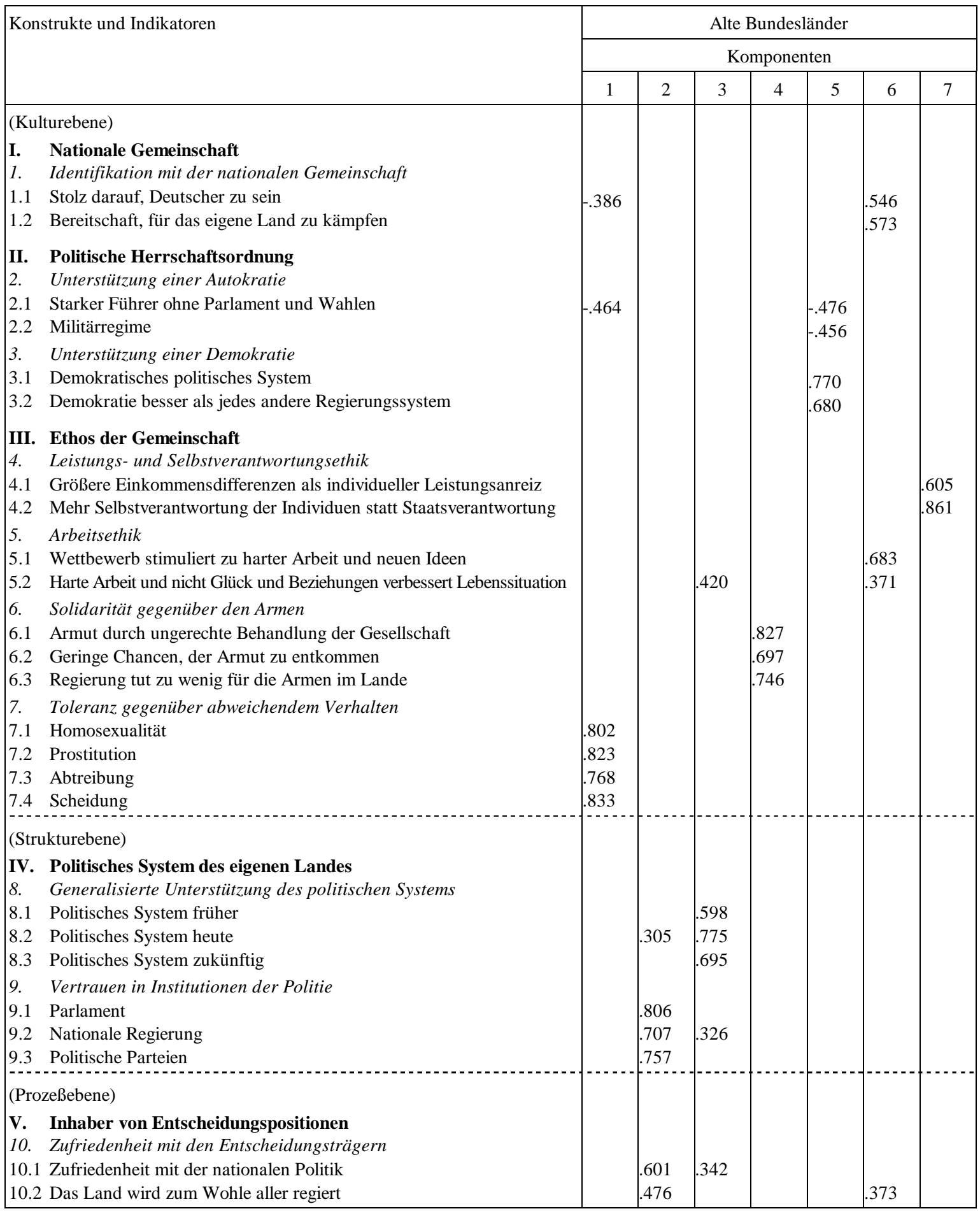

a Extraktionsmethode: Hauptkomponentenanalyse; Rotationsmethode: Varimax 
Tabelle 1.3: Dimensionen der Einstellungen der demokratischen Gemeinschaft in Deutschland, neue Bundesländer (Faktorenanalyse ${ }^{\mathrm{a}}$ )

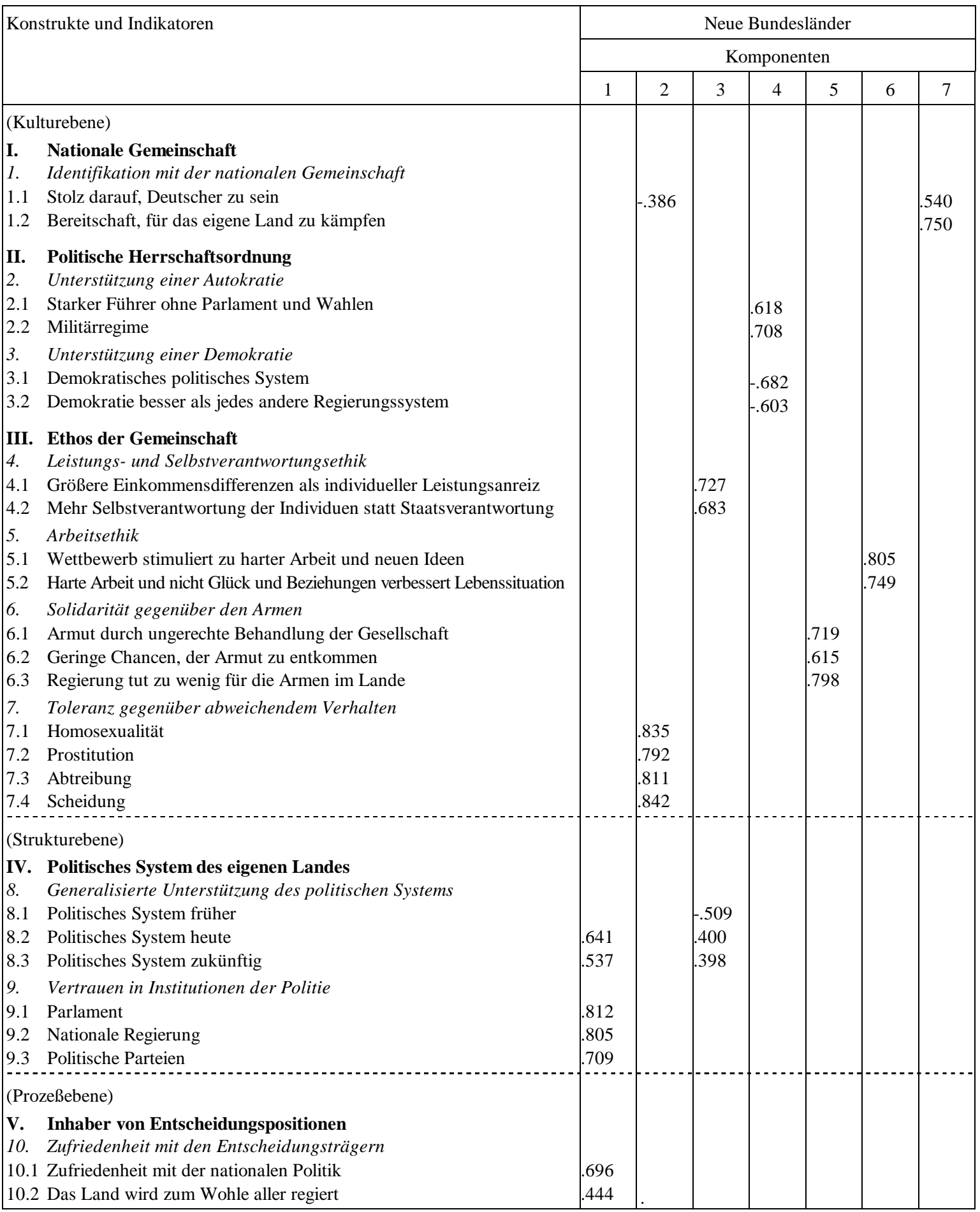

a Extraktionsmethode: Hauptkomponentenanalyse; Rotationsmethode: Varimax 
Die ,politische Herrschaftsordnung“ (II) enthält zwei Konstrukte: erstens die „Unterstützung einer Autokratie“ (2) und zweitens die „Unterstützung einer Demokratie“ (3). Die Einstellung zur Autokratie wird mit zwei Indikatoren erfaßt, die gebräuchliche Varianten dieser Herrschaftsordnung ansprechen: „Starker Führer ohne Parlament und Wahlen“ (2.1) und „Militärregime“ (2.2). Die Einstellung zur Demokratie wird einmal absolut und einmal relativ gemessen: „Demokratisches politisches System“ (3.1) und „Demokratie besser als jedes andere Regierungssystem“" (3.2).

Der „Ethos der Gemeinschaft“ (III) differenziert sich in vier Konstrukte. Die ersten beiden - „Leistungs- und Selbstverantwortungsethik“ (4) und „Arbeitsethik“ (5) - stellen ethische Vorstellungen über die individuelle Lebensgestaltung dar und die anderen beiden „Solidarität gegenüber den Armen“ (6) und „Toleranz gegenüber abweichendem Verhalten“ (7) ethische Vorstellungen über das Verhältnis zu den anderen Mitgliedern der Gemeinschaft. Mit Ausnahme der „Toleranz gegenüber abweichendem Verhalten“ können diese Konstrukte unschwer auf die Typologie demokratischer Gemeinschaften (s. Schaubild 1) bezogen werden.

Der Indikator „Größere Einkommensdifferenzen als individueller Leistungsanreiz“ (4.1) erfaßt den Konkurrenzaspekt bei der einen Dimension der Typologie (,Verhältnis der Individuen zueinander“). Der Indikator „Mehr Selbstverantwortung der Individuen statt Staatsverantwortung" (4.2) ist eine direkte Operationalisierung der anderen Dimension der Typologie („Verantwortung des Individuums für eigenes Lebensschicksal“). Die beiden Indikatoren der Arbeitsethik (5.1 und 5.2) nehmen eine Bewertung von „harter Arbeit“ vor. Im theoretischen Teil wurde festgestellt, daß eine Arbeitsethik sowohl zum calvinistischen als auch zum lutheranischen Protestantismus gehört. Aber vor allem im calvinistischen Ethos entfaltet sie eine hohe Motivationskraft, da der durch Arbeit und Leistung erzielte Erfolg im Leben ein Ausweis der eigenen Auserwähltheit durch Gott darstellen soll. Zudem ist im Unterschied zum Lutheranismus im Calvinismus mit der Arbeitsethik eine Differenz und eine Konkurrenz zu den anderen verbunden. Bezogen auf die Typologie des Schaubildes 1 betrachten wir deshalb eine überdurchschnittlich starke Arbeitsethik als einen empirischen Beleg einer libertären Gemeinschaft.

Die „Solidarität gegenüber den Armen“ (6) besteht aus drei Indikatoren, von denen zwei sich auf die gesellschaftlichen Bedingungen der Armut beziehen (6.1 und 6.2). Diesen indirekten Messungen liegt die Unterstellung zugrunde, daß weniger die Armen selbst für ihre Situation verantwortlich sind, als vielmehr die Gesellschaft und daß durch diese Einstellung eine Disposition für entsprechende solidarische Handlungen wie z. B. der Unterstützung der Armen durch die Regierung (4.3) gestiftet wird. Das Konstrukt erfaßt also weniger die konkrete Solidarität einer republikanischen Gemeinschaft, als vielmehr die abstrakte Solidarität einer sozialistischen Gemeinschaft.

In dem World Values Survey sind keine Indikatoren enthalten, die das - neben der Präferenz für eine demokratische Herrschaftsordnung - wichtigste Kriterium einer demokrati- 
schen Gemeinschaft erfassen: die Anerkennung der Anderen als Freie und Gleiche. Wir ziehen deshalb als Substitut die Toleranz gegenüber den anderen heran, die als eine Konsequenz oder als ein Ausdruck dieses basalen Wertes begriffen werden kann. Die in der Studie enthaltenen Toleranzindikatoren werden zu dem Konstrukt „Toleranz gegenüber abweichendem Verhalten“ (7) zusammengefaßt. Als Referenz für abweichendes Verhalten dienen geltende Verhaltensnormen für die Bereiche der Familie, Ehe und Sexualität. Diese Normen bilden den Kern der ethischen Vorstellungen jeder Gemeinschaft und stellen somit einen harten Test für Toleranz dar. Das Problem dieser Indikatoren liegt weniger in diesen ethischen Normen selbst als vielmehr in der Erfassung der Einstellung dazu. Es wurde gefragt, inwieweit diese Verhaltensweisen - Homosexualität, Prostitution, Abtreibung, Scheidung (7.1-7.4) - für gerechtfertigt gehalten werden oder nicht. Damit werden aber eher die eigenen Einstellungen zu diesen ethischen Normen erfragt und weniger die Toleranz gegenüber Abweichungen von anderen. Nach Walzer (1998) ist eine gewisse Relativierung der eigenen Auffassung jedoch die notwendige Bedingung der Toleranz gegenüber anderen Auffassungen. Und das Zugeständnis, daß diese anderen Auffassungen zumindest gerechtfertigt werden können, ist ein Ausdruck einer solchen Relativierung. Wir betrachten diese Indikatoren deshalb als einen zwar problematischen, aber dennoch brauchbaren Ersatz für eine valide Toleranzmessung.

Die nächste Ebene des demokratischen Systems ist die der Struktur, und das heißt der konkreten Demokratie des eigenen Landes. Das eine von zwei Konstrukten dieser Ebene bezieht sich auf die „generalisierte Unterstützung des politischen Systems“ (8). Die drei Indikatoren ( 8.1 bis 8.3 ) unterscheiden sich nur hinsichtlich der Zeitdimension: es wird nach dem politischen System früher, heute und zukünftig gefragt. Auf diese Weise soll eine grundlegende und längerfristige Einstellung erfaßt werden und nicht nur die Einschätzung der aktuellen Situation. Das andere Konstrukt erfaßt das „Vertrauen in Institutionen der Politie“ (9). Die entsprechenden Indikatoren beziehen sich auf das Parlament (9.1) und die Regierung (9.2) als den zentralen Institutionen der Legislative bzw. der Exekutive und auf die politischen Parteien (9.3) als den wichtigsten kollektiven Akteuren, die man als Gesamtheit ebenfalls als eine Institution betrachten kann.

Die unterste Systemebene ist die des Prozesses und diese hat zwei ganz unterschiedliche Bezugspunkte. Erstens die Inhaber der Entscheidungspositionen der Politie. Diese Akteure gestalten die politischen Entscheidungsprozesse und sie werden von den Bürgern gewählt oder abgewählt. Diese Wahlen sind die maßgebliche institutionelle Vorkehrung für die Steuerung des Handelns der Regierenden durch die Regierten. Der zweite Bezugspunkt sind die Bürger selbst, und zwar als aktive Teilnehmer am politischen Geschehen. In den Tabellen 1.1 bis 1.3 sind nur die Inhaber von Entscheidungspositionen (V) aufgenommen worden. Das auf sie bezogene Konstrukt ist die „Zufriedenheit mit den Entscheidungsträgern“ (10) und es wird durch zwei Indikatoren gebildet: erstens der ,Zufriedenheit mit der nationalen 
Politik“ (10.1), für die die Entscheidungsträger verantwortlich sind, und zweitens der Auffassung der Befragten, inwieweit „das Land zum Wohle aller regiert“ (10.2) wird.

Die aktive Teilnahme der Bürger selbst am politischen Geschehen bildet eine eigene Dimension auf der Prozeßebene, und die darauf bezogenen Indikatoren werden einer gesonderten Faktorenanalyse unterzogen. Die Ergebnisse sind in den Tabellen 2.1 bis 2.3 dargestellt. Auch in diesem Falle beginnen wir mit einer Erörterung der Indikatoren und ziehen dazu lediglich die Tabelle 2.1 heran.

Tabelle 2.1: Dimensionen des politischen Engagements der demokratischen Gemeinschaft in den USA (Faktorenanalyse ${ }^{\mathrm{a}}$ )

\begin{tabular}{|c|c|c|}
\hline \multirow[b]{3}{*}{ Konstrukte und Indikatoren } & \multicolumn{2}{|c|}{ USA } \\
\hline & \multicolumn{2}{|c|}{ Komponenten } \\
\hline & 1 & 2 \\
\hline (Prozeßebene) & & \\
\hline 1. Politische Motivation & & \\
\hline 1.1 Diskussion mit Freunden über Politik & .651 & \\
\hline 1.2 Interesse an Politik & .669 & \\
\hline $\begin{array}{ll}\text { 2. } & \text { Illegitimität von Gewaltanwendung im Bereich der Politik } \\
\text { 2.1 } & \text { Illegitimität von Gewaltanwendung im Bereich der Politik }\end{array}$ & & \\
\hline 3. Konformität mit Legalitätsnormen & & \\
\hline 3.1 Beanspruchung ungerechtfertigter Leistungen vom Staat & & .772 \\
\hline 3.2 Schwarzfahren & & .811 \\
\hline 3.3 Steuerhinterziehung, wenn eine Möglichkeit besteht & & .713 \\
\hline 4. Beteiligung an Protestaktionen & & \\
\hline 4.1 Unterzeichnung einer Petition & .625 & \\
\hline 4.2 Beteiligung an einer legalen Demonstration & .764 & \\
\hline 4.3 Beteiligung an einem Boykott & .768 & \\
\hline $\begin{array}{l}\text { 5. Aktive Mitgliedschaft in freiwilligen Assoziationen } \\
\text { 5.1 Aktives Mitglied in mehr als einer Assoziation }\end{array}$ & .505 & \\
\hline
\end{tabular}

a Extraktionsmethode: Hauptkomponentenanalyse; Rotationsmethode: Varimax

Die Konstrukte und Indikatoren, die in der Tabelle 2.1 verzeichnet sind, beziehen sich teilweise auf Einstellungen zu Verhalten und teilweise auf Verhalten selbst. Bei den Einstellungen wird davon ausgegangen, daß diese starke Dispositionen für faktische Beteiligung darstellen. Das erste Konstrukt des politischen Engagements der Bürger wird als „Politische Motivation“ (1) bezeichnet und es wird durch die beiden Indikatoren „Diskussion mit Freunden über Politik“(1.1) und „Interesse an Politik“ (1.2) gebildet. Ohne daß ein nennenswerter Anteil der Bürger eine gewisse politische Motivation aufweist, ist eine funktionierende und lebendige Demokratie nicht denkbar. Es existiert allerdings kein theoretisches Kriterium, das angibt, wie groß dieser Anteil denn genau sein sollte. 
Tabelle 2.2: Dimensionen des politischen Engagements der demokratischen Gemeinschaft in Deutschland, alte Bundesländer (Faktorenanalyse ${ }^{\mathrm{a}}$ )

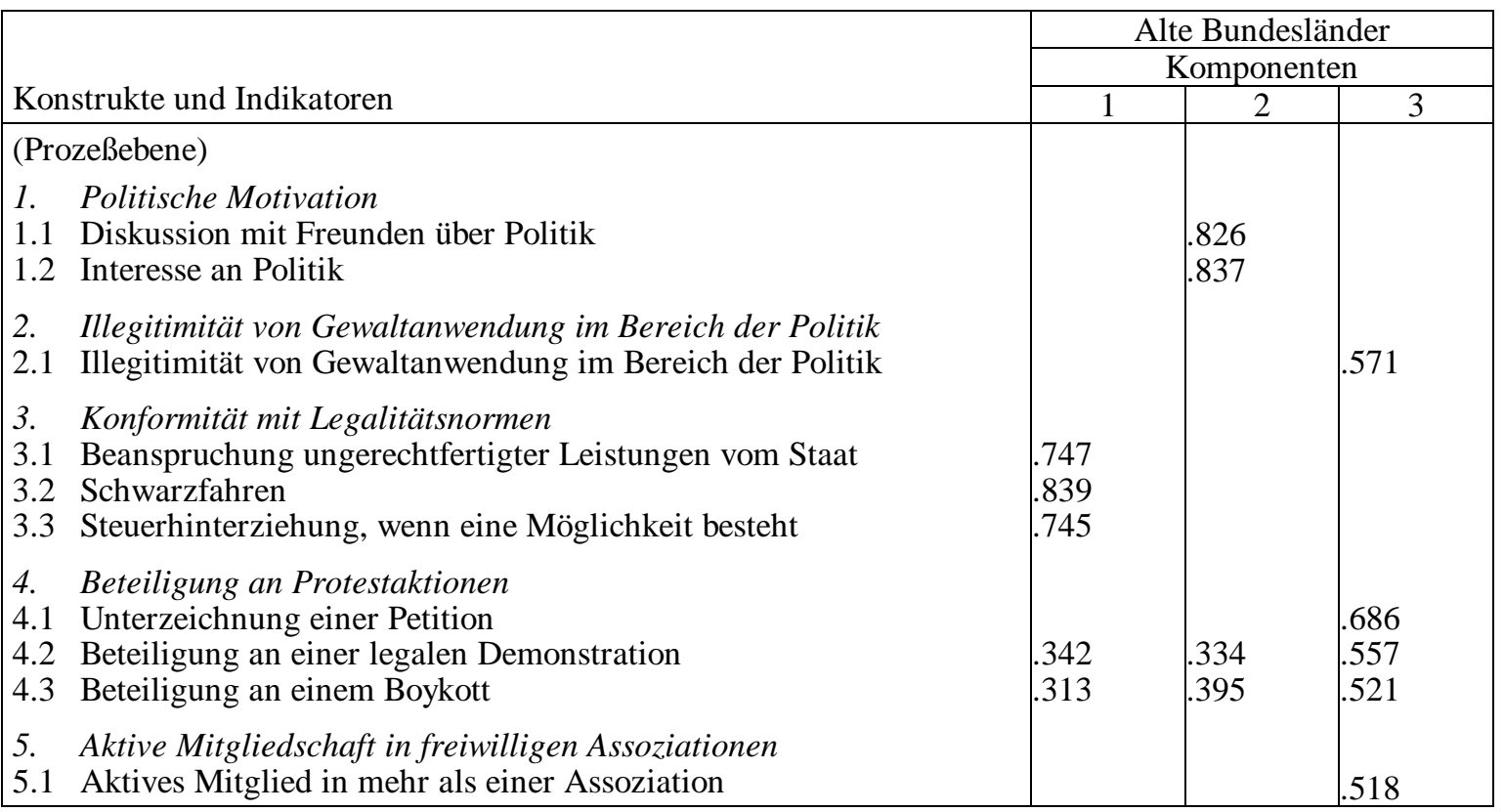

a Extraktionsmethode: Hauptkomponentenanalyse; Rotationsmethode: Varimax

Tabelle 2.3: Dimensionen des politischen Engagements der demokratischen Gemeinschaft in Deutschland, neue Bundesländer (Faktorenanalyse ${ }^{\mathrm{a}}$ )

\begin{tabular}{|c|c|c|c|c|}
\hline \multirow{3}{*}{ Konstrukte und Indikatoren } & \multirow{2}{*}{\multicolumn{4}{|c|}{$\begin{array}{c}\text { Neue Bundesländer } \\
\text { Komponenten }\end{array}$}} \\
\hline & & & & \\
\hline & 1 & 2 & 3 & 4 \\
\hline (Prozeßebene) & \multirow{6}{*}{$\begin{array}{l}800 \\
.870 \\
.839\end{array}$} & \multirow{6}{*}{$\begin{array}{l}.785 \\
.738 \\
.749\end{array}$} & \multirow{6}{*}{.857} & \multirow{6}{*}{.885} \\
\hline $\begin{array}{ll}\text { 1. } & \text { Politische Motivation } \\
\text { 1.1 } & \text { Diskussion mit Freunden über Politik } \\
\text { 1.2 } & \text { Interesse an Politik }\end{array}$ & & & & \\
\hline $\begin{array}{ll}\text { 2. Illegitimität von Gewaltanwendung im Bereich der Politik } \\
\text { 2.1 Illegitimität von Gewaltanwendung im Bereich der Politik }\end{array}$ & & & & \\
\hline $\begin{array}{ll}\text { 3. } & \text { Konformität mit Legalitätsnormen } \\
\text { 3.1 } & \text { Beanspruchung ungerechtfertigter Leistungen vom Staat } \\
\text { 3.2 } & \text { Schwarzfahren } \\
\text { 3.3 } & \text { Steuerhinterziehung, wenn eine Möglichkeit besteht }\end{array}$ & & & & \\
\hline $\begin{array}{ll}\text { 4. } & \text { Beteiligung an Protestaktionen } \\
\text { 4.1 } & \text { Unterzeichnung einer Petition } \\
4.2 & \text { Beteiligung an einer legalen Demonstration } \\
4.3 & \text { Beteiligung an einem Boykott }\end{array}$ & & & & \\
\hline $\begin{array}{l}\text { 5. Aktive Mitgliedschaft in freiwilligen Assoziationen } \\
\text { 5.1 Aktives Mitglied in mehr als einer Assoziation }\end{array}$ & & & & \\
\hline
\end{tabular}

a Extraktionsmethode: Hauptkomponentenanalyse; Rotationsmethode: Varimax 
In der Hypothese 4 (s. Abschnitt 3.1) wird die Abwesenheit von politischen Gewalthandlungen als ein wesentliches Kriterium einer demokratischen Gemeinschaft auf der Prozeßebene postuliert. Das Konstrukt ,Illegitimität von Gewaltanwendung im Bereich der Politik“ (2) und der entsprechende Indikator (2.1) fragen aber nach der Illegitimität von Gewalt und erfassen somit eine Einstellung zur Gewaltnorm und können deshalb keine Messung von faktischen Gewalthandlungen sein. Da uns aber eine solche Handlungsmessung nicht zur Verfügung steht, verwenden wir diese Einstellungsmessung als einen Ersatz. Das ist u. E. deshalb vertretbar, weil sich die erfragte Einstellung auf eine Handlungsform bezieht und nach sozialpsychologischer Auffassung derartige handlungsbezogene Einstellungen starke Dispositionen für faktische Handlungen bedeuten (Ajzen 1988). Unter dieser Prämisse haben wir auch ein weiteres Konstrukt auf der Prozeßebene eingeführt.

Das Konstrukt „Konformität mit Legalitätsnormen“ (3) bezieht sich auf Verhaltensnormen im öffentlichen Bereich. Es geht dabei um „Beanspruchung ungerechtfertigter Leistungen vom Staat“ (3.1), „Schwarzfahren“ (3.2) und „Steuerhinterziehung, wenn eine Möglichkeit besteht“ (3.3). Einerseits muß von einer demokratischen Gemeinschaft erwartet werden, daß sie die Verhaltensnormen im öffentlichen Bereich befolgt, die durch demokratische Verfahren gesetzt und somit legitimiert sind. Das bedeutet bei diesen Verhaltensweisen natürlich, daß sie sie nicht ergreifen. Andererseits handelt es sich bei diesen Verhaltensnormen um relativ „schwache“ Normen, was sich auch in den verhältnismäßig geringen staatlichen Sanktionen bei Normverletzung ausdrückt. Eine eindeutige Beziehung zu einer demokratischen Gemeinschaft läßt sich von dem Ausmaß der Konformität mit diesen Legalitätsnormen deshalb nicht herstellen. Die Interpretation der empirischen Befunde muß sich aus diesem Grunde auf den Vergleich zwischen den Ländern beschränken.

Die letzten beiden Konstrukte der Tabelle 2.1 erfassen reale politische Beteiligung der Bürger. Die „Beteiligung an Protestaktionen“ (4) stützt sich auf Indikatoren, die im Rahmen des Political-Action-Projektes entwickelt und analysiert wurden (Kaase und Marsh 1979; Kaase 1990): „Unterzeichnung einer Petition“ (4.1), „Beteiligung an einer legalen Demonstration“ (4.2) und „Beteiligung an einem Boykott“ (4.3). Während sich diese drei Indikatoren auf eine begrenzte Beteiligung an bestimmten Aktionsformen beziehen, geht es bei dem Konstrukt „Aktive Mitgliedschaft in freiwilligen Assoziationen“ (5) um eine dauerhafte Beteiligung im Rahmen einer Gruppe mit einer bestimmten Organisationsstruktur. Wie bereit ausgeführt wurde, ist die Mitarbeit in freiwilligen Assoziationen eines der wichtigsten Merkmale der civic community von Putnam (1993). Und sowohl die Beteiligung an Protestaktionen als auch die Mitarbeit in freiwilligen Assoziationen sind kennzeichnend für eine civil society. 


\subsubsection{Empirische Ergebnisse}

Der erste Schritt der empirischen Analyse besteht in der Klärung, ob und inwieweit sich die theoretisch angenommenen Konstrukte auch empirisch halten lassen. Zu diesem Zweck werden - jeweils getrennt für die politischen Einstellungen und das politische Engagement der Bürger - exploratorische Faktorenanalysen ausgeführt. Wir gehen zunächst auf die Ergebnisse für die politischen Einstellungen ein, die in den Tabellen 1.1 bis 1.3 abgetragen sind. Die Erwartung ist, daß die zu den Konstrukten zusammengefaßten Indikatoren auch jeweils einen Faktor bilden und auf diesem Faktor möglichst hoch laden.

Das ist bei den meisten Konstrukten auch der Fall. In allen drei Gemeinschaften gibt es aber zwei wichtige Ausnahmen. Erstens bilden die Indikatoren für Autokratie und Demokratie einen gemeinsamen Faktor. Das ist angesichts der Tatsache, daß es sich bei Autokratie und Demokratie um die beiden gegensätzlichen politischen Herrschaftsordnungen handelt, wenig überraschend. Die Befragten haben ganz offensichtlich konsistent geantwortet. Das drückt sich technisch auch in den umgekehrten Vorzeichen der Indikatoren für Demokratie einerseits und Autokratie andererseits aus.

Zweitens sind die Einstellungen zum politischen System (8), zu den Institutionen der Politie (9) und zu den Inhabern den Entscheidungsträgern (10) nicht trennscharf. In den USA bilden die Einstellungen zum politischen System und zu den Entscheidungsträgern einen Faktor, in den alten Bundesländern ist gleiches für die Einstellungen zu den politischen Institutionen und zu den Entscheidungsträgern festzustellen, und in den neuen Bundesländern bilden alle Indikatoren zum politischen System, zu den politischen Institutionen und zu den Entscheidungsträgern einen Faktor. Aus diesen empirischen Ergebnissen muß die Schlußfolgerung gezogen werden, daß in allen drei Gemeinschaften die Indikatoren zum politischen System eher eine Einschätzung der Wirklichkeit der Demokratie des eigenen Landes erfassen als eine Einstellung zu dem Typ der Demokratie, so wie er in der Verfassung festgelegt ist. Ebenso erfaßt das gemessene Vertrauen in die politischen Institutionen weniger eine Einstellung zu diesen Institutionen als Teil des strukturellen Arrangements des demokratischen Systems, sondern vielmehr eine Bewertung der politischen Akteure, die in diesem Institutionen agieren (Gabriel 1999). Die beiden Konstrukte, die wir theoretisch der Strukturebene zugeordnet haben - „Generalisierte Unterstützung des politischen Systems“ (8) und „Vertrauen in Institutionen der Politie“ (9) - messen also strukturbezogene Einstellungen bestenfalls teilweise.

Wir wollen die Ergebnisse dieser Faktorenanalysen nicht ausführlich erläutern, sondern lediglich auf einige interessante Details verweisen. In den USA (s. Tabelle 1.1) laden die beiden Indikatoren zur „Unterstützung einer Demokratie“ (3.1 und 3.2) positiv auf den Faktor für „Identifikation mit der nationalen Gemeinschaft“ (1). Offenbar haben in den USA viele Bürger gleichzeitig eine Identifikation mit der nationalen Gemeinschaft und eine Präferenz für eine demokratische Herrschaftsordnung. Wie eine Korrelationsanalyse zeigt (deren 
Ergebnisse hier nicht ausgewiesen werden), gibt es in beiden Teilen Deutschlands demgegenüber eine signifikante Negativkorrelation zwischen der „Identifikation mit der nationalen Gemeinschaft“ und der „Unterstützung einer Demokratie“. In dieser Negativkorrelation schlägt sich vermutlich die geschichtliche Erfahrung des Nationalsozialismus nieder, in dem sich ein übersteigerter Nationalismus mit einer autokratischen Herrschaftsordnung verbunden hatte.

Aufschlußreich sind auch die Nebenladungen der Unterstützung des ,Politischen Systems früher" (8.1) in den USA und in den neuen Bundesländern. In den USA (s. Tabelle 1.1) lädt dieser Indikator im Sinne der theoretischen Erwartung positiv auf dem Faktor für die „Generalisierte Unterstützung des politischen Systems“ (8). Daneben lassen sich in den USA aber auch „Nebenladungen“ auf den Faktoren für „Leistungs- und Selbstverantwortungsethik“ (4) und für „Arbeitsethik“ (5) feststellen. Diese sind sogar stärker als die theoretisch postulierte „Hauptladung“. Sofern diese beiden Konstrukte des „Ethos der Gemeinschaft“ Kernelemente des „American ethos“ darstellen, wird dieser „American ethos“ offenbar eher mit dem früheren politischen System verbunden als mit dem heutigen. Möglicherweise wird mit dem früheren politischen System ein minimalerer Staat im Sinne der libertären Ideologie assoziiert als mit dem heutigen.

Genau entgegengesetzt können die Ergebnisse für die neuen Bundesländer interpretiert werden (s. Tabelle 1.3). Danach lädt die Unterstützung des „Politischen Systems früher“ (8.1), was in diesem Falle das staatssozialistische System der DDR meint, negativ auf den Faktor, der sich auf die „Leistungs- und Selbstverantwortungsethik“ (4) bezieht. Eine starke Befürwortung dieser Ethik korreliert also mit einer starken Ablehnung des früheren Systems der DDR und umgekehrt. Das entspricht vollkommen der theoretischen Erwartung, da genau diese Leistungs- und Selbstverantwortungsethik von dem früheren DDR-System weder propagandistisch vertreten noch institutionell gefördert wurde.

Wir gehen im folgenden auf die Ergebnisse der Faktorenanalysen für das politische Engagement der Bürger in den drei Gemeinschaften ein. In den USA (s. Tabelle 2.1) ist der erste Faktor so etwas wie ein genereller Engagementfaktor. Er umfaßt die Indikatoren der Konstrukte „Politische Motivation“ (1), „Beteiligung an Protesten“ (4) und „Aktive Mitgliedschaft in freiwilligen Assoziationen“ (5). Die Indikatoren der „Konformität mit Legalitätsnormen“ (3) konstituieren einen eigenen Faktor. Die „Illegitimität von Gewaltanwendung im Bereich der Politik“ (2) bildet weder einen eigenen Faktor noch lädt sie auf einem der beiden anderen Faktoren. Für die Bürger der USA handelt es sich dabei offenbar um eine ganz eigenständige Dimension.

In den alten Bundesländern (s. Tabelle 2.2) läßt sich ebenfalls ein genereller Engagementfaktor feststellen (3. Faktor). Er bezieht die Indikatoren der „Beteiligung an Protestaktionen“ (4) und der „Aktiven Mitgliedschaft in freiwilligen Organisationen“ (5) ein und - im Unterschied zu den USA - ebenfalls die „Illegitimität von Gewaltanwendung im Bereich der Politik“ (2). Die Indikatoren der „Politischen Motivation“ (1) und der „Konformität mit 
Legalitätsnormen“ (3) bilden jeweils eigene Faktoren. Auf diesen beiden Faktoren haben zwei der Protestindikatoren („Beteiligung an einer legalen Demonstration“, „Beteiligung an einem Boykott“") nennenswerte Nebenladungen. Das kann als ein Ausdruck dafür interpretiert werden, daß beide Protestformen in den alten Bundesländern völlig normale Beteiligungsweisen ohne jede Assoziationen an Illegitimität geworden sind.

Die Faktorstruktur für die neuen Bundesländer (s. Tabelle 2.3) ist die differenzierteste. Hier bilden alle Konstrukte mit mehr als einem Indikator - „Politische Motivation“ (1), „Konformität mit Legalitätsnormen“ (2) und „Beteiligung an Protestaktionen“ (4) - jeweils einen Faktor. Der vierte Faktor besteht überraschenderweise aus „Illegitimität von Gewaltanwendung im Bereich der Politik“ (2) und aus „Aktive Mitgliedschaft in freiwilligen Assoziationen“ (5). Bemerkenswert dabei ist, daß die Vorzeichen der jeweiligen Faktorladungen gegenläufig sind, die Illegitimität von Gewalt also negativ mit der aktiven Mitgliedschaft in freiwilligen Assoziationen kovariiert. Eine Interpretation dieses Ergebnisses können wir nicht anbieten.

Insgesamt sind die Ergebnisse dieser Faktorenanalysen für das Engagement der Bürger unklarer als die für die politischen Einstellungen. Die theoretisch postulierten Konstrukte lassen sich empirisch weniger eindeutig auffinden und die Unterschiede zwischen den Ländern sind erheblich größer. Dieser Sachverhalt hat sicherlich auch mit der Unterschiedlichkeit der Indikatoren zu tun, die in diese Faktorenanalysen eingegangen sind.

\subsection{Ausprägungen der Einstellungen der demokratischen Gemeinschaften}

In diesem Abschnitt soll überprüft werden, inwieweit die im theoretischen Teil der Analyse vorgebrachten Behauptungen über die gesellschaftlichen Gemeinschaften in den USA und in den beiden Teilen Deutschlands empirisch bestätigt werden können. Das bezieht sich vor allem auf die Einstufung aller drei Gemeinschaften als demokratische und auf die Klassifikation der USA als einer demokratisch-libertären - mit einigen republikanischen Elementen der alten Bundesländer als einer demokratisch-liberalen und der neuen Bundesländer als einer demokratisch-sozialistischen Gemeinschaft. Die Grundlage der empirischen Überprüfung stellen die Ausprägungen der Indikatoren dar, die bereits erläutert wurden. Diese Ausprägungen sind in den Tabellen 3 und 4 aufgeführt. 
Tabelle 3: Politische Einstellungen der demokratischen Gemeinschaft in den USA und Deutschland

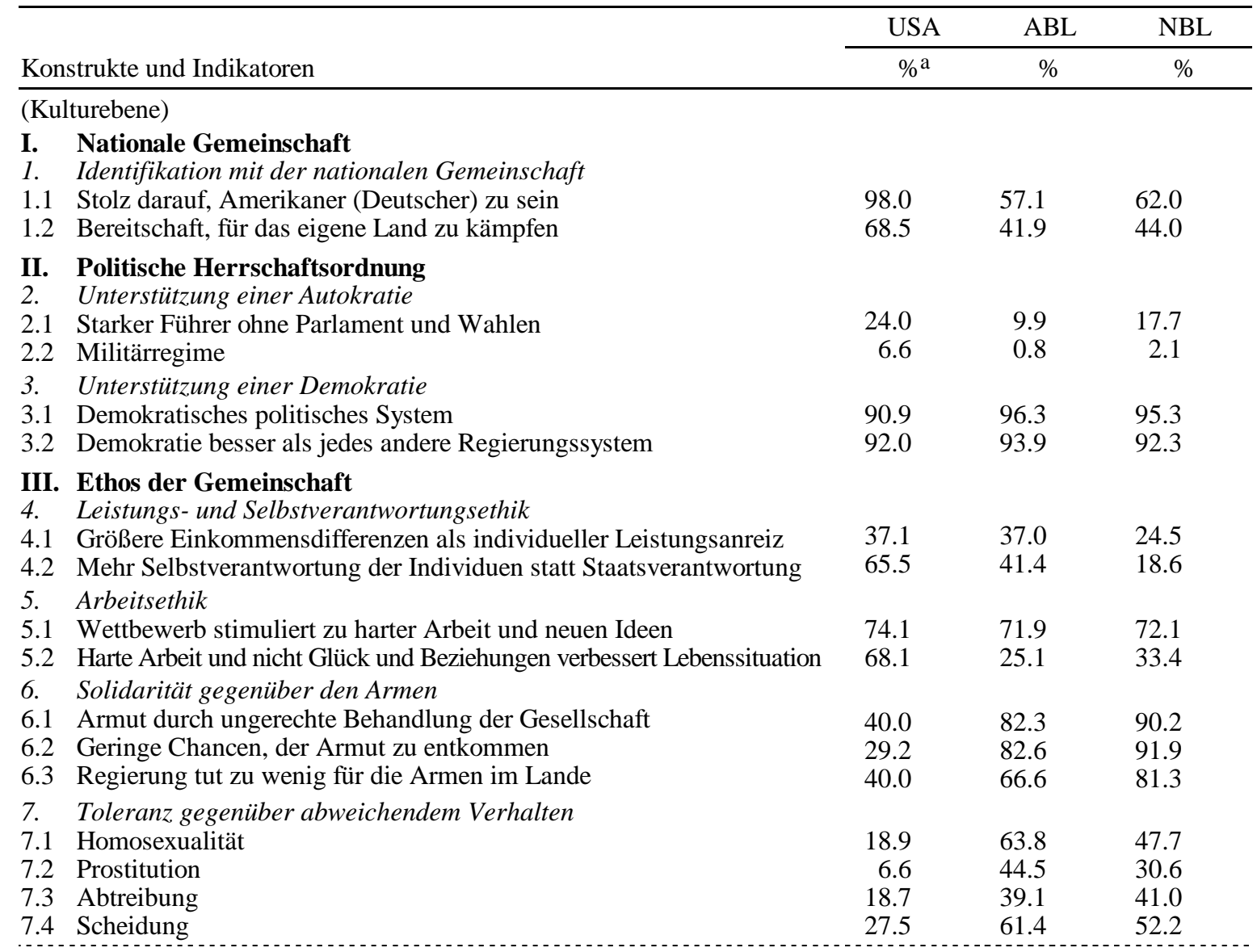

(Strukturebene)

IV. Politisches System des eigenen Landes

8. Generalisierte Unterstützung des politischen Systems

8.1 Politisches System früher

8.2 Politisches System heute

8.3 Politisches System zukünftig

9. Vertrauen in Institutionen der Politie

9.1 Parlament

9.2 Nationale Regierung

9.3 Politische Parteien

(Prozeßebene)

V. Inhaber von Entscheidungspositionen

10. Zufriedenheit mit den Entscheidungsträgern

10.1 Zufriedenheit mit der nationalen Politik $\quad 48.6 \quad 32.7 \quad 30.0$

10.2 Das Land wird zum Wohle aller regiert

26.7

35.9

$24.6^{\mathrm{b}}$

$\begin{array}{lll}36.0 & 58.4 & 24.6 \\ 22.1 & 26.3 & 20.8\end{array}$

$\begin{array}{lll}22.1 & 26.3 & 20.8 \\ 37.6 & 26.0 & 22.3\end{array}$

$\begin{array}{lll}29.8 & 29.4 & 16.7\end{array}$

$30.7 \quad 24.0 \quad 17.0$

$\begin{array}{lll}21.8 & 13.9 & 10.2\end{array}$

a Die Einstellungen wurden mit verschiedenen Skalen gemessen. Bei 4er Skalen wird eine Dichotomisierung vorgenommen und bei 10er Skalen werden nur die Werte von 7-10 berücksichtigt, die beiden mittleren Kategorien werden als Ausdruck von Indifferenz genommen.

b Bezieht sich auf das System der DDR.

Umfrage: World Values Survey 1995-1997 
Wir wenden uns zunächst der Frage der demokratischen Gemeinschaft zu und ziehen dazu die Kriterien heran, die in Hypothesenform in Abschnitt 3.2 formuliert wurden. Im Sinne der Hypothese H1, die sich auf Präferenzen hinsichtlich der politischen Herrschaftsordnung bezieht, können alle drei Gemeinschaften eindeutig als demokratische bezeichnet werden. Über 90 Prozent der Befragten unterstützen nach beiden Indikatoren (3.1 und 3.2) eine Demokratie und durchschnittlich fast 90 Prozent lehnen eine Autokratie (2.1 und 2.2) ab. Dieses günstige Gesamtbild wird durch die Tatsache, daß in den neuen Bundesländern 17.7 und in den USA 24.0 Prozent einen „starken Führer ohne Parlament und Wahlen“ (2.1) befürworten, nicht wesentlich beeinträchtigt. Möglicherweise hängt diese relativ hohe Zustimmung in den USA mit der Institution der Präsidentschaft zusammen und der Vorstellung, daß zur Lösung bestimmter nationaler Probleme der Präsident durch den Kongreß als der anderen Institution des „divided government“ weniger behindert werden sollte, als das häufig der Fall ist.

Tabelle 4: Politisches Engagement der demokratischen Gemeinschaft in den USA und Deutschland

\begin{tabular}{|c|c|c|c|c|c|c|}
\hline \multirow[b]{2}{*}{ Konstrukte und Indikatoren } & \multicolumn{2}{|c|}{ USA } & \multicolumn{2}{|r|}{$\mathrm{ABL}$} & \multicolumn{2}{|c|}{ NBL } \\
\hline & \multicolumn{2}{|r|}{$\%$} & \multicolumn{2}{|r|}{$\%$} & \multicolumn{2}{|r|}{$\%$} \\
\hline \multicolumn{7}{|l|}{ (Prozeßebene) } \\
\hline 1. Politische Motivation & \multirow{2}{*}{\multicolumn{2}{|c|}{73.2}} & \multirow{2}{*}{\multicolumn{2}{|c|}{89.6}} & \multirow{2}{*}{\multicolumn{2}{|c|}{88.5}} \\
\hline 1.1 Diskussion mit Freunden über Politik & & & & & & \\
\hline 1.2 Interesse an Politik & \multicolumn{2}{|c|}{64.2} & \multicolumn{2}{|c|}{77.9} & \multicolumn{2}{|c|}{75.7} \\
\hline 2. Illegitimität von Gewaltanwendung & \multirow{2}{*}{\multicolumn{2}{|c|}{83.1}} & \multirow{2}{*}{\multicolumn{2}{|c|}{85.3}} & \multirow{2}{*}{\multicolumn{2}{|c|}{85.2}} \\
\hline 2.1 Ablehnung von Gewalt als Mittel der Politik & & & & & & \\
\hline 3. Konformität mit Legalitätsnormen & & & & & & \\
\hline 3.1 Beanspruchung ungerechtfertigter Leistungen vom Staat & \multicolumn{2}{|c|}{75.8} & \multicolumn{2}{|c|}{57.5} & \multicolumn{2}{|c|}{65.8} \\
\hline 3.2 Schwarzfahren & \multicolumn{2}{|c|}{67.5} & \multicolumn{2}{|c|}{38.6} & \multicolumn{2}{|c|}{51.3} \\
\hline 3.3 Steuerhinterziehung, wenn eine Möglichkeit besteht & \multicolumn{2}{|c|}{74.3} & \multicolumn{2}{|c|}{40.1} & \multicolumn{2}{|c|}{53.7} \\
\hline \multicolumn{7}{|l|}{ 4. Beteiligung an Protestaktionen } \\
\hline 4.1 Unterzeichnung einer Petition & 71.2 & $(90.9)^{\mathrm{a}}$ & 65.9 & $(96.1)$ & 57.4 & $(93.8)$ \\
\hline 4.2 Beteiligung an einer legalen Demonstration & 15.6 & $(56.5)$ & 25.7 & (74.9) & 21.9 & $(77.4)$ \\
\hline 4.3 Beteiligung an einem Boykott & 19.2 & $(61.3)$ & 18.1 & $(74.3)$ & 11.2 & $(57.3)$ \\
\hline 5. Aktive Mitgliedschaft in freiwilligen Assoziationen & \multirow{2}{*}{\multicolumn{2}{|c|}{52.1}} & \multirow{2}{*}{\multicolumn{2}{|c|}{25.2}} & \multirow{2}{*}{\multicolumn{2}{|c|}{15.6}} \\
\hline 5.1 Aktives Mitglied in mehr als einer Assoziation & & & & & & \\
\hline
\end{tabular}

Das Kriterium der Hypothese $\mathrm{H} 2$ besteht in der Anerkennung der Anderen als Freie und Gleiche. Aufgrund fehlender Indikatoren können wir dieses Kriterium nicht zu einer empirischen Klärung der Frage verwenden, inwieweit eine demokratische Gemeinschaft jeweils vorliegt. Wir können als Ersatz lediglich die Toleranz gegenüber den Anderen heranziehen, die hier als „Toleranz gegenüber abweichendem Verhalten“(7) operationalisiert ist. 
Die höchste Toleranz weisen nach drei der vier Indikatoren die alten Bundesländer auf. Nur bei der Frage der „Abtreibung“ (7.3) liegen die neuen Bundesländer etwas höher als die alten. Die Toleranz der Amerikaner ist nach unseren Daten bei den vier Indikatoren erheblich niedriger als in den beiden Teilen Deutschlands. Diese sehr geringe Toleranz hat sicherlich mit den konkreten Verhaltensnormen zu tun, die bei den Indikatoren bewertet werden sollen: Homosexualität, Prostitution, Abtreibung und Scheidung (7.1-7.4). Diese betreffen gerade die ethischen Kernbereiche, auf die sich der von Lipset (1996) und von anderen festgestellte moralische Rigorismus des „American ethos“ bezieht, der letztlich auf die protestantischen Sekten zurückgeht. In anderen Handlungsbereichen und bei anderen Handlungsnormen sind die Toleranzen der amerikanischen Bürger vermutlich erheblich größer, und demzufolge ist das Bild, das durch unsere Daten präsentiert wird, sicherlich verkürzt. Aber dennoch erfaßt auch diese eingeschränkte Toleranzmessung einen relevanten Wirklichkeitsaspekt in den USA. Das wird z. B. daran deutlich, daß eine Erfüllung dieser Handlungsnormen ein wichtiges Beurteilungskriterium der Politiker durch die amerikanischen Bürger ist. Das wird auch an den politischen Auseinandersetzungen deutlich, die sich an Streitfragen entzünden, die sich direkt auf diese Handlungsnormen beziehen. Die Abtreibungsfrage ist hier nur ein besonders prominentes Issue.

Die Hypothese H3 postuliert eine Unterstützung oder Ablehnung der Demokratie des eigenen Landes aufgrund der Anwendung demokratischer Standards als ein Merkmal einer demokratischen Gemeinschaft. Die in der Tabelle 3 aufgeführten Ergebnisse zur ,generalisierten Unterstützung des politischen Systems“ (8) und zum „Vertrauen in Institutionen der Politie“ (9) müßten deshalb einigermaßen bedenklich stimmen. Sowohl die Unterstützung des politischen Systems als auch das Vertrauen in die Institutionen der Politie ist in allen drei Gemeinschaften nur gering ausgeprägt. Sogar dem Parlament als den institutionellen Kern einer repräsentativen Demokratie vertrauen weniger als ein Drittel der Bürger. Wie die Faktorenanalysen aber gezeigt haben, bezieht sich diese Unterstützung und das Vertrauen vor allem auf die Entscheidungsträger, die innerhalb des Systems und der Politie handeln, und weniger auf eine Einstellung zu dem System und der Politie selbst. Zudem wissen wir nichts über die individuellen Motive der geäußerten Einstellungen, so daß schon von daher kein unmittelbarer Bezug zu der Hypothese H3 hergestellt werden kann. Dieser empirische Befund kann also nicht zu einer weiteren Klärung der Frage dienen, inwieweit die drei Gemeinschaften einer demokratischen entsprechen.

Auf der Prozeßebene ist der möglichst geringe Einsatz von Gewalthandlungen als politisches Mittel das wichtigste Kriterium einer demokratischen Gemeinschaft (vgl. Hypothese 4). In der von uns analysierten Studie sind keine entsprechenden Indikatoren enthalten, und wir haben deshalb als Ersatzmessung die „Illegitimität von Gewalthandlungen“ (2) herangezogen. Die Ergebnisse der Tabelle 4 zeigen, daß in allen drei Gemeinschaften Gewalt ganz überwiegend als illegitim betrachtet wird, obwohl in der entsprechenden Frage offen gelassen wird, ob sich die Gewalt als mögliches Mittel auf die eigene Gesellschaft bezieht oder 
auf andere Gesellschaften. Unter denjenigen Befragten, die die Gewaltanwendung nicht als illegitim erachtet haben, dürften deshalb auch einige gewesen sein, die dabei an den Einsatz von Gewalt etwa zur Befreiung Kuwaits von Saddam Hussein im Golfkrieg, an die Befriedung Bosniens und ähnliches gedacht haben.

Die Hypothese H5 postuliert die Befolgung von demokratisch gesetzten Rechtsnormen im politischen Handeln. Auch wenn wir die Indikatoren der „Konformität mit Legalitätsnormen" eher als schwache Messungen des Konstruktes eingeschätzt haben, so ist doch einigermaßen überraschend, daß in den alten Bundesländern durchschnittlich weniger als die Hälfte und in den USA durchschnittlich fast drei Viertel der Befragten eine entsprechende Folgebereitschaft ausdrücken. Dieses Ergebnis entspricht ganz und gar nicht der von Lipset (1996) getroffenen Behauptung, daß die Amerikaner eine gegenüber den Europäern erheblich geringere Neigung haben, staatlich gesetzten Verhaltensnormen zu folgen. Allerdings sieht das Bild ganz anders aus, wenn man sich auf weniger ,weiche“ Rechtsnormen bezieht, sondern auf solche mit einem eindeutig kriminellen Charakter. Wie die offiziellen Kriminalitätsstatistiken zeigen, sind darauf bezogene Normverletzungen in den USA erheblich gröBer als in Europa und vor allem auf solche Statistiken bezieht sich Lipset. Diese in den USA überdurchschnittliche Bereitschaft zum Einsatz auch krimineller Mittel zur Erreichung allgemein akzeptierter Ziele ist schon von Merton (1968) festgestellt worden und führte zur Entwicklung seines Anomiekonzeptes.

Die Hypothese H6 formuliert eine möglichst hohe Beteiligung der Bürger an nationalen Wahlen als ein demokratisches Kriterium. Ein Indikator für Wahlbeteiligung fehlt aber in dem World Values Survey. Die Wahlbeteiligung ist jedoch aus den nationalen Wahlstatistiken bekannt. Danach beteiligen sich in Deutschland immer noch die ganz überwiegende Mehrheit der Bürger zumindest an den Bundestagswahlen, während in den USA an den Präsidentschaftswahlen und den Kongreßwahlen durchschnittlich kaum die Hälfte der Bürger teilnehmen. Nach diesen objektiven Daten müßte die USA als weniger demokratisch eingestuft werden als die beiden Teile Deutschlands. Die Beteiligung an nationalen Wahlen ist aber nur die eine Seite der Medaille, denn in den USA gibt es - wie bereits erwähnt sehr viel häufiger Wahlen als in den meisten europäischen Ländern und das vor allem auf der Ebene der Bundesstaaten und der Kommunen. Und wie die im europäischen Vergleich relativ geringe Wahlbeteiligung der Schweiz zeigt, geht die Häufigkeit von Wahlen mit einer relativ geringen Beteiligung an den einzelnen Wahlen einher. Häufige Wahlen müssen aber sicherlich als ein demokratisches Kriterium auf der strukturellen Ebene angesehen werden.

Zudem läßt sich nicht nur in den Zeiten Tocquevilles, sondern auch noch heute eine gegenüber Europa erheblich höhere Mitarbeit der Bürger in freiwilligen Assoziationen feststellen. Das zeigen auch die Ergebnisse der Tabelle 4. Danach sind in den USA mehr als die Hälfte aller Bürger ,aktives Mitglied in mehr als einer Assoziation“ (5.1). Der entsprechende Prozentsatz für die alten Bundesländer ist nur halb so groß und in den neuen Bundesländern beträgt er lediglich 15.6 Prozent. Das republikanische Modell der Demokratie 
sieht gerade diese Beteiligungsform der Bürger als besonders wichtig für die Selbstorganisation der Gemeinschaft an, und dementsprechend kann dieser empirische Befund als der Beleg eines republikanischen Elementes der amerikanischen Gemeinschaft interpretiert werden.

Insgesamt bestätigen die vorgelegten empirischen Ergebnisse relativ eindeutig, daß alle drei gesellschaftlichen Gemeinschaften entsprechend unserer theoretischen Annahme als demokratische gelten können. Dieses Ergebnis deckt sich auch mit denen von anderen Studien. Im nächsten Analyseschritt greifen wir die in der empirischen Forschung eher vernachlässigte Frage auf, inwieweit die USA sowie die alten und die neuen Bundesländer die unterschiedlichen Typen der demokratischen Gemeinschaft repräsentieren, wie wir theoretisch angenommen haben. Bei der empirischen Überprüfung dieser Annahmen stützen wir uns auf die Typologie demokratischer Gemeinschaften (s. Schaubild 1) und die auf sie bezogenen Hypothesen (Hypothesen H7-H10). Für die Klassifikation der drei Gemeinschaften in dieser Typologie sind lediglich Konstrukte des „Ethos der Gemeinschaft“ bedeutsam. Für die Dimension „Verantwortung des Individuums für eigenes Lebensschicksal“ ist in erster Linie das Konstrukt „Leistungs- und Selbstverantwortungsethik“ (4) und in zweiter Linie das der „Arbeitsethik“ (5) relevant. Für die Dimension „Verhältnis der Individuen zueinander“ können wir hier nur die „Solidarität gegenüber den Armen“ (6) heranziehen. Bei der Interpretation der empirischen Befunde zu den drei Einstellungen gehen wir relativ vor, das heißt wir stellen fest, inwieweit der Vergleich zwischen den drei Gemeinschaften den theoretischen Erwartungen entspricht.

Die beiden kontrastierenden Gemeinschaften sind die demokratisch-libertäre und die demokratisch-sozialistische. Ersterer haben wir die USA und letzterer die neuen Bundesländer zugeordnet. Dementsprechend müßten sich die beiden Gemeinschaften am stärksten voneinander unterscheiden und die alten Bundesländer jeweils zwischen ihnen liegen. Das ist bei dem Indikator, der sich auf die Alternative von Staatsverantwortung vs Selbstverantwortung bezieht (4.2), in einem frappierenden Ausmaß der Fall. In den USA befürworten 65.5 Prozent der Bürger mehr Selbstverantwortung gegenüber der Staatsverantwortung, in den alten Bundesländern sind das 41.4 Prozent und in den neuen Bundesländern lediglich 18.6. Prozent. Dieses Ergebnis ist unseres Erachtens deshalb überraschend eindeutig, weil der Indikator nach „mehr“ Selbstverantwortung fragt. In die Antwort der Befragten fließt also zwangsläufig auch der von ihnen wahrgenommene Status quo des eigenen Landes mit ein. In den USA ist die Selbstverantwortung aber faktisch schon viel stärker ausgeprägt ist als in Deutschland und dennoch wünscht die klare Mehrheit der amerikanischen Bürger eine weitere Zunahme dieser Selbstverantwortung. Demgegenüber besitzt Deutschland einen der ausgebautesten Wohlfahrtsstaaten und dennoch befürwortet in den alten Bundesländern ein beträchtlicher Anteil der Befragten eine weitere Zunahme der Staatsverantwortung und in den neuen Bundesländern ist das die ganz überwiegende Mehrheit. 
Weniger eindeutig sind die Resultate zur ,größeren Einkommensdifferenzierung als individueller Leistungsanreiz" (4.1). Hier unterscheiden sich lediglich die neuen Bundesländer von den anderen beiden Gemeinschaften. In den neuen Bundesländern präferieren 24.5 Prozent der Befragten größere Einkommensdifferenzen, während das in den USA und in den alten Bundesländern circa 37 Prozent sind. Aber auch im diesen Falle ist die gegebene Wirklichkeit zu berücksichtigen. Der Indikator fragt nach einer Vergrößerung der Einkommensunterschiede und diese sind in den USA aber bereits erheblich und auch deutlich ausgeprägter als in Deutschland.

Die Befunde zur „Arbeitsethik“ (5) sind uneinheitlich und bestätigen die theoretischen Erwartungen nur teilweise. Nach dem Indikator „Wettbewerb stimuliert zu harter Arbeit und neuen Ideen“ (5.1) weisen alle drei Länder eine gleichermaßen hohe Arbeitsethik auf. Dieser Indikator ist aber eine problematische Messung. Zum einen wird in erster Linie nach dem Wettbewerb gefragt und die „harte Arbeit“ als eine Konsequenz dieses Wettbewerbs gesehen. Zum anderen wird dieser Wettbewerb nicht auf die Konkurrenz zwischen den Individuen auf den Märkten mit der Möglichkeit eines Mißerfolges bezogen, sondern eben auf „harte Arbeit“ und auf ,neue Ideen“. Der Indikator weist also für die Messung der Arbeitsethik im Sinne des calvinistischen Ethos nur eine eingeschränkte Validität auf und kann deshalb auch kaum zu einer empirischen Klärung der Frage verwendet werden, welche demokratische Gemeinschaft die drei Länder jeweils repräsentieren. Demgegenüber ist der andere Indikator „Harte Arbeit und nicht Glück und Beziehungen verbessert Lebenssituation“ (5.2) eine angemessene Messung der Arbeitsethik des Calvinismus der protestantischen Sekten. Die im Vergleich sehr hohe Zustimmung in den USA (68,1 Prozent) und die vergleichsweise niedrige in den beiden Teilen Deutschlands entspricht deshalb auch den Erwartungen.

Die „Solidarität gegenüber den Armen“ (6) zeigt die erwarteten Unterschiede. Nach allen drei Indikatoren ist die (abstrakte) Solidarität in den USA erheblich geringer als in den beiden Teilen Deutschlands und in den alten Bundesländern ist sie geringer als in den neuen. Zumindest der Indikator „Regierung tut zu wenig für die Armen im Lande“ (6.3) dürfte die wahre Differenz zwischen USA und Deutschland eher noch unterschätzen, da faktisch für die Armen in Deutschland wesentlich mehr getan wird als in den USA. Trotzdem meinen 81.3 Prozent der Befragten in den neuen Bundesländern, daß die Regierung zu wenig für die Armen im Lande tut, und 66.6 Prozent meinen das in den alten Bundesländern. Der entsprechende Prozentsatz für die USA ist demgegenüber nur 40 Prozent.

Die präsentierten empirischen Ergebnisse berechtigen unseres Erachtens zur Aufrechterhaltung der Annahme, daß die demokratische Gemeinschaft der USA eine demokratischlibertäre, die der alten Bundesländer eine demokratisch-liberale und die der neuen Bundesländer eine demokratisch-sozialistische ist. Die unterschiedliche Klassifikation der beiden Teile Deutschlands stützen wir empirisch auf die Differenzen der dargestellten Ergebnisse. Diese Befunde werden aber auch durch die Ergebnisse anderer Studien bestätigt, die sich 
auf normative Einstellungen zur Demokratie beziehen. Danach gibt es zwischen den beiden Teilen Deutschlands seit Beginn der Deutschen Einheit bis heute eine signifikante Differenz bei der relativen Priorität von Freiheit bzw. Gleichheit und bei der Einschätzung des Sozialismus als Idee (Fuchs 1997b).

Für die USA wurden neben ihrer Klassifikation als demokratisch-libertäre Gemeinschaft auch einige republikanische Elemente konstatiert. Das stützt sich empirisch auf die geringe „Toleranz gegenüber abweichendem Verhalten“ hinsichtlich bestimmter ethischer Vorstellungen und auf die sehr hohe Aktivität in freiwilligen Assoziationen. Angesichts der absoluten Zentralität des Individualismus im „American ethos“ (McClosky und Zaller 1984; Ladd 1994; Lipset 1996) und dem damit verbundenen eindeutigen Vorrang der Rechte des Individuums vor den Pflichten der Gemeinschaft, kann die demokratische Gemeinschaft der USA dennoch nicht als eine republikanische bezeichnet werden.

\section{Schlußfolgerungen}

Das Demokratieprinzip zielt immer auf die Implementation einer demokratischen Herrschaftsordnung in konkreten Ländern ab. Die Frage der Demokratie wird also in den einzelnen Ländern der Welt entschieden. Die Vorstellung einer supranationalen Demokratie, die im Kontext der Globalisierungsdebatte entwickelt wurde, verändert diesen Sachverhalt nicht grundsätzlich, sondern nur die Größenordnung der Etablierung einer Demokratie. Mit der inneren Dynamik des Demokratieprinzips ist das Postulat verbunden, daß eine existierende Demokratie auch Bestand haben müsse.

Eine der wichtigsten Bestandsbedingungen einer demokratischen Herrschaftsordnung ist eine dazu kongruente gesellschaftliche Gemeinschaft. Das ist eine der grundlegenden Annahmen des Paradigmas der Politischen Kultur und diese ist durch die empirische Demokratieforschung vielfach bestätigt worden. Unter dieser Prämisse kann eine bestehende Demokratie in zweifacher Weise in Frage gestellt werden. Erstens, wenn die gesellschaftliche Gemeinschaft eine autokratische ist. Das kann zum Beispiel der Fall sein, wenn einem bestimmten Land durch externe Mächte eine Demokratie quasi verordnet wird, ohne daß dies ihre Entsprechung in der gesellschaftlichen Gemeinschaft hat. In diesem Falle würde von der gesellschaftlichen Gemeinschaft ein permanenter Druck auf die Wiedereinführung eines autokratischen Systems ausgehen, der in gewisser Weise mit der internationalen Mächtekonstellation konkurrierte, die auf die Beibehaltung demokratischer Herrschaftsordnungen drängt. Beispiele dafür lassen sich in nahezu allen Weltregionen finden.

Zweitens kann eine bestehende Demokratie dadurch in Frage gestellt werden, daß der strukturelle Typ der Demokratie, der durch die Verfassung des Landes implementiert ist, nicht mit den normativen Demokratievorstellungen der Bürger kongruent ist. In diesem Falle ist die gesellschaftliche Gemeinschaft zwar eine demokratische, aber sie präferiert eine 
andere Form der Demokratie als die des eigenen Landes. Für eine derartige Konstellation kann es verschiedene Ursachen geben. Beispielsweise kann eine ursprüngliche Kongruenz von Kultur und Struktur durch einen Wertewandel gestört werden. Oder Elitengruppen eines Landes implementieren eine Demokratie unter Bezugnahme auf externe Beispiele, ohne daß dies durch die entsprechenden Einstellungen der Bürger abgedeckt ist. Auch dafür gibt es genügend Beispiele.

Alle drei gesellschaftlichen Gemeinschaften, die wir analysiert haben, sind zweifelsohne demokratische Gemeinschaften. Die Demokratie der jeweiligen Länder kann deshalb auch nicht grundsätzlich bedroht sein, denn kaum jemand will eine Autokratie. Eine der Behauptungen und eines der Ergebnisse unserer Analyse besteht aber darin, daß die Bürger der USA und der beiden Teile Deutschlands jeweils einen anderen Typ der demokratischen Gemeinschaft repräsentieren und dementsprechend auch unterschiedliche normative Demokratievorstellungen aufweisen. Wie vertragen sich diese normativen Orientierungen mit der demokratischen Herrschaftsordnung des eigenen Landes?

Bei der Darstellung der kulturellen Tradition Amerikas wurde erläutert, daß die Einrichtung der amerikanischen Demokratie ein relativ unmittelbarer Ausdruck der herrschenden Kultur war. Die amerikanische Verfassung des 18. Jahrhunderts kann deshalb als ein exemplarischer Fall einer selektiven Implementation kultureller Werte für den Bereich der Politik durch Rechtsnormen gelten. Die libertäre Gemeinschaft der USA hat sich eine libertäre Demokratie mit einem schwachen Staat und einer starken Gewaltenteilung geschaffen. Diese Kongruenz von Kultur und Struktur ist auch durch die gesellschaftlichen Wandlungsprozesse des 19. und vor allem des 20. Jahrhunderts nicht nachhaltig gestört worden. Erstens ist der ideologische Kern des „American ethos“ erhalten geblieben und zweitens gewährleistete gerade die Offenheit der amerikanischen Demokratie gegenüber dem Demos entsprechende Anpassungen an veränderte Umweltbedingungen. Diese Anpassung führte aber nicht zu der Entwicklung eines neuen Typus der Demokratie. Die Kritik an der heutigen amerikanischen Demokratie entspringt hauptsächlich aus der Perspektive der ethischen Werte des „American ethos“ und der ursprünglichen Vorstellungen über die Rolle des Staates. Das drückt sich unter anderem in einer relativen Verschiebung der politischen Prioritäten der Amerikaner zum konservativen Pol der ideologischen Liberal-KonservativDimension spätestens seit Reagan aus.

In den alten Bundesländern gab es den erwähnten Import einer demokratischen Herrschaftsordnung von außen. Die Väter des deutschen Grundgesetzes waren zwar Deutsche, aber sie repräsentierten sicherlich nicht die Auffassungen und Werthaltungen der Durchschnittsbürger kurz nach dem Ende des Zweiten Weltkrieges. Im Verlaufe der nachfolgenden Jahrzehnte hat sich in (West-)Deutschland aber eine demokratisch-liberale Gemeinschaft herausgebildet, die zu der demokratischen Herrschaftsordnung des Grundgesetzes kompatibel war. Wie komparative Studien zeigen, wurde die Demokratie der Bundesrepublik von ihren Bürgern seit etwa Anfang der siebziger Jahre im Vergleich den etablierten 
Demokratien des Westens sogar überdurchschnittlich akzeptiert. Die Bürger der alten Bundesländer wollen seitdem keine andere Demokratie als die, die sie bereits haben. Auch in der Bundesrepublik Deutschland hat sich demzufolge eine Kongruenz von Kultur und Struktur herausgebildet, und das bedeutet konkreter eine Kongruenz von liberaler Gemeinschaft und liberaler Demokratie.

Die Bürger der neuen Bundesländer stellen demgegenüber eine demokratisch-sozialistische Gemeinschaft dar, was vor allem auf die Sozialisation im DDR-Sozialismus zurückgeht, der seinerseits längerfristige kulturelle Traditionen aufgegriffen und stabilisiert hat. In den neuen Bundesländern dominieren demzufolge normative Demokratievorstellungen, die nicht mit der liberalen Demokratie des vereinigten Deutschland kompatibel sind. Die Unterstuitzung dieser Demokratie ist demzufolge auch sehr gering. Inwieweit sich diese Einstellungen als ein entsprechender Anpassungsdruck auf die Demokratie der Bundesrepublik auswirken können, soll hier offen gelassen werden. Eine gegenläufige Tendenz dazu wird zum einen durch die vorherrschenden Einstellungen der Bürger der alten Bundesländern und zum anderen durch die Zwänge der Globalisierung erzeugt.

Vor allem die ökonomische Globalisierung führt nach verbreiteter Auffassung zu einem Bedeutungsverlust der Nationalstaaten und zu einer Verringerung seiner politischen Steuerungsfähigkeit (Habermas 1998; Münch 1998; Scharpf 1998; Zürn 1998). Gerade diese Steuerungsfähigkeit ist aber für eine liberale Demokratie und noch mehr für eine sozialistische Demokratie mit ihren marktergänzenden und marktbeschränkenden Politiken zur Herstellung sozialer Sicherheit und Gerechtigkeit von entscheidender Bedeutung. Angesichts dieses Tatbestandes kann gefragt werden, ob die libertäre Gemeinschaft der USA mit ihren individualistischen und meritokratischen Werthaltungen nicht besser für die Herausforderungen einer Demokratie im Zeitalter der Globalisierung gerüstet ist als die meisten europäischen Gesellschaften. Die Annahme, daß der kompetitive Individualismus und die ihm entsprechende libertäre Gemeinschaft eine höhere Anpassungsfähigkeit an die Restriktionen eines expandierenden Weltmarktes und einer reduzierten Steuerungsfähigkeit der Nationalstaaten aufweist als der solidarische Etatismus, ist zumindest nicht unplausibel. Die normative Frage, wie eine Demokratie aussehen sollte und wie von daher gesehen eine bestehende Demokratie zu beurteilen ist, ist eine andere Frage und kann auch unabhängig von diesen praktischen Zwängen diskutiert werden. 



\section{Literatur}

Ajzen, Icek, 1988: Attitudes, Personality, and Behavior. Milton Keynes: Open University Press.

Almond, Gabriel A., 1980: The Intellectual History of the Civic Culture Concept. S. 1-36 in: Gabriel A. Almond und Sidney Verba (Hg.): The Civic Culture Revisited, Boston/Toronto: Little, Brown \& Company.

Almond, Gabriel A., und Sidney Verba, 1963: The Civic Culture. Political Attitudes and Democracy in Five Nations. Princeton: Princeton University Press.

Baker, Kendell L., Russell J. Dalton und Kai Hildebrandt, 1981: Germany Transformed. Political Culture and the New Politics. Cambridge, Mass./London: Harvard University Press.

Barnes, Samuel H., Max Kaase u.a., 1979: Political Action: Mass Participation in Five Western Democracies. Beverly Hills, Cal.: Sage.

Berry, Christopher J., 1989: The Idea of a Democratic Community. New York: St. Martin's Press.

Chapman, John W., und Ian Shapiro (Hg.), 1993: Democratic Community. Nomos No. XXXV. New York: New York University Press.

Cohen, Jean L., und Andrew Arato, 1992: Civil Society and Political Theory. Cambridge: MIT Press.

Conradt, David P., 1980: The Changing German Political Culture. S. 212-272 in: Gabriel A. Almond und Sidney Verba (Hg.): The Civic Culture Revisited. Boston/Toronto: Little, Brown and Company.

Dahrendorf, Ralf, 1965: Gesellschaft und Demokratie in Deutschland. München: R. Piper.

Easton, David, 1965: A Framework for Political Analysis. Englewood Cliffs, N. J.: Prentice-Hall.

Etzioni, Amitai, 1996: The New Golden Rule. Community and Morality in a Democratic Society. New York: Basic Books.

Ferree, Myra Marx, William A. Gamson, Jürgen Gerhards und Dieter Rucht, 2000: Collective Actors and the Public Sphere. Abortion Discourse in the U.S. and Germany. Cambridge, Mass.: Cambridge University Press (in Vorbereitung).

Fuchs, Dieter, 1989: Die Unterstützung des politischen Systems der Bundesrepublik Deutschland. Opladen: Westdeutscher Verlag.

Fuchs, Dieter, 1997a: Welche Demokratie wollen die Deutschen? Einstellungen zur Demokratie im vereinigten Deutschland. S. 81-113 in: Oscar W. Gabriel (Hg.): Politische Orientierungen und Verhaltensweisen im vereinigten Deutschland. Opladen: Leske + Budrich. 
Fuchs, Dieter, 1997b: Wohin geht der Wandel der demokratischen Institutionen in Deutschland? Die Entwicklung der Demokratievorstellungen der Deutschen seit ihrer Vereinigung. S. 253-284 in: Gerhard Göhler (Hg.): Institutionenwandel, Sonderheft 16 des Leviathan. Opladen: Westdeutscher Verlag.

Fuchs, Dieter, 1998: Kriterien demokratischer Performanz in Liberalen Demokratien. S. 151-179 in: Michael Greven (Hg.): Demokratie - eine Kultur des Westens? 20. Wissenschaftlicher Kongreß der Deutschen Vereinigung für Politische Wissenschaft. Opladen: Leske + Budrich.

Fuchs, Dieter, 1999: Soziale Integration und politische Institutionen in modernen Gesellschaften. In: Jürgen Friedrichs und Wolfgang Jagodzinski (Hg.): Soziale Integration. Sonderheft 39 der Kölner Zeitschrift für Soziologie und Sozialpsychologie (im Erscheinen).

Fuchs, Dieter, Jürgen Gerhards und Edeltraud Roller, 1993: Wir und die anderen. Ethnozentrismus in den zwölf Ländern der europäischen Gemeinschaft, in: Kölner Zeitschrift für Soziologie und Sozialpsychologie 45: 238-253.

Fuchs, Dieter, und Edeltraud Roller, 1998: Cultural Conditions of Transition to Liberal Democracies in Central and Eastern Europe. in: S. 35-77 in: Samuel H. Barnes und János Simon (Hg.): The Postcommunist Citizen. Budapest: Erasmus Foundation and Hungarian Academy of Sciences.

Gabriel, Oscar W., 1997: Politische Orientierungen und Verhaltensweisen im Transitionsprozeß. S. 10-33 in: Oscar W. Gabriel (Hg.): Politische Orientierungen und Verhaltensweisen im vereinigten Deutschland. Opladen: Leske + Budrich.

Gabriel, Oscar W., 1999: Integration durch Institutionenvertrauen? Struktur und Entwicklung des Verhältnisses der Bevölkerung zum Parteienstaat und zum Rechtsstaat im vereinigten Deutschland. In: Jürgen Friedrichs und Wolfgang Jagodzinski (Hg.): Soziale Integration. Sonderheft 39 der Kölner Zeitschrift für Soziologie und Sozialpsychologie (im Erscheinen).

Habermas, Jürgen, 1992a: Drei normative Modelle der Demokratie: Zum Begriff deliberativer Politik. S. 11-24 in: Manfred Münkler (Hg.): Die Chancen der Freiheit. Grundprobleme der Demokratie. Für Iring Fetscher zum 70. Geburtstag. München/Zürich: R. Piper.

Habermas, Jürgen, 1992b: Faktizität und Geltung. Beiträge zur Diskurstheorie des Rechts und des demokratischen Rechtsstaats. Frankfurt a. M.: Suhrkamp.

Habermas, Jürgen, 1996: Die Einbeziehung des Anderen. Studien zur politischen Theorie. Frankfurt a. M.: Suhrkamp.

Habermas, Jürgen, 1998: Die postnationale Konstellation. Politische Essays. Frankfurt a. M.: Suhrkamp.

Hofstadter, Richard, 1964: The American Political Tradition and the Men Who Made it. New York: Alfred A. Knopf.

Hofstadter, Richard, 1972: The Age of Reform. From Bryan to F.D.R. New York: Alfred A. Knopf. 
Jennings, M. Kent, Jan W. van Deth u.a., 1990: Continuities in Political Action. A Longitudinal Study of Political Orientations in Three Western Democracies. Berlin/New York: Walter de Gruyter.

Kaase, Max, und Alan Marsh, 1979: Political Action. A Theoretical Perspective. S. 27-56 in: Samuel H. Barnes, Max Kaase u. a.: Political Action. Mass Participation in Five Western Democracies. Beverly Hills/London: Sage.

Kaase, Max, 1990: Mass Participation, S. 23-64 in: M. Kent Jennings, Jan van Deth u. a.: Continuities in Political Action. A Longitudinal Study of Political Orientations in Three Western Democracies. Berlin/New York: Walter de Gruyter.

Keane, John (Hg.), 1988: Civil Society and the State. New European perspectives. London/New York: Verso.

Kielmansegg, Peter Graf, 1996: Integration und Demokratie. S. 47-71 in: Markus Jachtenfuchs und Beate Kohler-Koch (Hg.): Europäische Integration. Opladen: Leske+Budrich.

Krieger, Leonard, 1957: The German Idea of Freedom. History of a Political Tradition. Boston: Beacon Press.

Ladd, Everett Carll, 1994: The American Ideology. An Exploration of the Origins, Meaning, and Role of American Political Ideas, Storrs. Conn.: Roper Center, University of Connecticut.

Lepsius, M. Rainer, 1995: Das Legat zweier Diktaturen für die demokratische Kultur im vereinigten Deutschland. S. 25-39 in: Everhard Holtmann und Heinz Sahner (Hg.): Aufhebung der Bipolarität - Veränderungen im Osten, Rückwirkungen im Westen. Opladen: Leske + Budrich.

Linz, Juan J., und Alfred Stepan, 1996: Problems of Democratic Transition and Consolidation: Southern Europe, South America, and Post-Communist Europe. Baltimore: Johns Hopkins University.

Lipset, Seymour Martin, 1996: American Exceptionalism. A Double-Edged Sword. New York: W. W. Norton.

McClosky, Herbert, und John Zaller, 1984: The American Ethos: Public Attitudes Toward Capitalism and Democracy. Cambridge, MA.: Harvard University Press.

Merton, Robert K., 1968: Social Structure and Anomie. S. 185-214 in: Robert K. Merton: Social Theory and Social Structure. New York/London: The Free Press.

Münch, Richard, 1986: Die Kultur der Moderne. Frankfurt a. M.: Suhrkamp.

Münch, Richard (1998). Globale Dynamik, lokale Lebenswelten. Der schwierige Weg in die Weltgesellschaft. Frankfurt a. M.: Suhrkamp.

Nettl, John P., 1968: The State as a Conceptual Variable, in: World Politics 20: 559-592.

Nisbet, Robert A., 1966: The Sociological Tradition. New York: Basic Books.

Parsons, Talcott, 1971: The System of Modern Societies. Englewood Cliffs, N.J: Prentice Hall. 
Plessner, Helmuth, 1974: Die verspätete Nation. Über die politische Verführbarkeit bürgerlichen Geistes. Frankfurt a. M.: Suhrkamp Taschenbuch Verlag.

Post, Robert C., 1993: Between Democracy and Community: The Legal Constitution of Social Form. S. 163-190 in: John W. Chapman und Ian Shapiro (Hg.): Democratic Community. Nomos No. XXXV. New York: New York University Press.

Putnam, Robert D., 1993: Making Democracy Work. Civic Traditions in Modern Italy. Princeton, N. J.: Princeton University Press.

Rawls, John, 1993: Political Liberalism. New York: Columbia University Press.

Rohrschneider, Robert, 1999: Learning Democracy. Democratic and Economic Values in Unified Germany. Oxford: Oxford University Press.

Roller, Edeltraud, 1992: Einstellungen der Bürger zum Wohlfahrtsstaat der Bundesrepublik Deutschland. Opladen: Westdeutscher Verlag.

Roller, Edeltraud, 1997: Sozialpolitische Orientierungen nach der deutschen Vereinigung. S. 115-146 in: Oscar W. Gabriel (Hg.): Politische Orientierungen und Verhaltensweisen im vereinigten Deutschland. Opladen: Leske + Budrich.

Scharpf, Fritz W., 1998: Demokratische Politik in der internationalen Ökonomie. S. 81-103 in: Michael Greven (Hg.): Demokratie - eine Kultur des Westens? 20. Wissenschaftlicher Kongreß der Deutschen Vereinigung für Politische Wissenschaft. Opladen: Leske + Budrich.

Schluchter, Wolfgang, 1996: Neubeginn durch Anpassung? Studien zum ostdeutschen Übergang, Frankfurt a. M.: Suhrkamp.

Schmidt, Gunnar, 1995: Zivile Gesellschaft und öffentlicher Raum, in: Leviathan 4: 562579.

Shell, Kurt L., 1989: Amerikanische Einstellungen zur Armut und sozialen Ungleichheit S. 11-24 in: Diether Döring und Richard Hauser (Hg.): Politische Kultur und Sozialpolitik. Ein Vergleich der Vereinigten Staaten und der Bundesrepublik Deutschland unter besonderer Berücksichtigung des Armutsproblems. Frankfurt a. M.: Campus.

Sternberger, Dolf, 1990: Verfassungspatriotismus. Frankfurt a. M.: Insel Verlag.

Taylor, Charles, 1993: Der Begriff der ,bürgerlichen Gesellschaft' im politischen Denkens des Westens. S. 117-148 in: Micha Brumlik und Hauke Brunkhorst (Hg.): Gemeinschaft und Gerechtigkeit. Frankfurt a. M.: Fischer Taschenbuch-Verlag.

Walzer, Michael, 1996: Zivile Gesellschaft und amerikanische Demokratie. Frankfurt a. M.: Fischer Taschenbuch Verlag.

Walzer, Michael, 1998: Über Toleranz. Von der Zivilisation der Differenz. Hamburg: Rotbuch-Verlag.

Weber, Max, 1988: Gesammelte Aufsätze zur Religionssoziologie. Vol. 1-3. Tübingen: Mohr. 
Wiesenthal, Helmut, 1996: Die Transition Ostdeutschlands: Dimensionen und Paradoxien eines Sonderfalls. S. 10-38 in: Helmut Wiesenthal (Hg.): Einheit als Privileg. Vergleichende Perspektiven auf die Transformation Ostdeutschlands. Frankfurt a. M.: Campus.

Zürn, Michael, 1998: Regieren jenseits des Nationalstaates. Frankfurt a.M.: Suhrkamp. 

Forschungsschwerpunkt III "Sozialer Wandel, Institutionen und Vermittlungsprozesse“

\section{Auswahl der Arbeitspapiere (Stand: September 1999)}

\section{Abteilungsübergreifend}

FS III 96-301 The Mass Media and Modern Government Kenneth Newton

FS III 96-302 Das intermediäre System der Politik als Orientierungssystem der Bürger Dieter Fuchs, Edeltraud Roller, Dieter Rucht und Bernhard Weßels

\section{Abteilung 1 "Öffentlichkeit und soziale Bewegungen"}

FS III 90-101 Strukturen und Funktionen moderner Öffentlichkeit. Fragestellungen und Ansätze. Jürgen Gerhards und Friedhelm Neidhardt

FS III 92-101 Anbieter von öffentlichen politischen Veranstaltungen in West-Berlin.

Barbara Blattert

Nachfrager und wahrgenommenes Angebot von öffentlichen politischen Veranstaltungen in der Bundesrepublik.

Jürgen Gerhards

FS III 92-103 Dokumentation und Analyse von Protestereignisssen in der Bundesrepublik Deutschland (Prodat), Codebuch.

Dieter Rucht, Peter Hocke und Thomas Ohlemacher

FS III 93-101 Westeuropäische Integration und die Schwierigkeiten der Entstehung einer europäischen Öffentlichkeit.

Jürgen Gerhards

FS III 93-102 Selbstkontrolle in den Medien: Der Deutsche Presserat und seine Möglichkeiten. Jessica Eisermann

FS III 93-103 Prominenz in der Bundesrepublik.

Birgit Peters

FS III 94-101 Von den Oppositionsgruppen der DDR zu den neuen sozialen Bewegungen in Ostdeutschland?

Barbara Blattert, Dieter Rink und Dieter Rucht

FS III 95-101 A Burning Question: Explaining the Rise of Racist and Extreme Right Violence in Western Europe.

Ruud Koopmans

FS III 95-103 German Unification, Democratization and the Role of Social Movements: A Missed Opportunity.

Dieter Rucht

FS III 95-105 Diskursanalyse im Zeit- und Ländervergleich. Methodenbericht über eine systematische Inhaltsanalyse zur Erfassung des öffentlichen Diskurses über Abtreibung in den USA und der Bundesrepublik in der Zeit von 1970 bis 1994.

Jürgen Gerhards und Monika Lindgens

FS III 97-101 Citizenship, National Identity and the Mobilisation of the Extreme Right. A Comparison of France, Germany, the Netherlands and Switzerland

Ruud Koopmans and Hanspeter Kriesi

FS III 98-101 Proteststrukturen im Ost-West-Vergleich 1989 - 1992

Susann Burchardt 
FS III 98-103 Die Branchenstruktur der Markt- und Meinungsforschung in der Bundesrepublik Deutschland von 1986 bis 1996. Eine deskriptive Analyse

Simone Wack

FS III 98-104 Konjunkturen der NS-Bewegung. Eine Untersuchung der Veranstaltungsaktivitäten der Münchener NSDAP, 1925-1930

Helmut K. Anheier, Friedhelm Neidhardt und Wolfgang Vortkamp

FS III 98-105 Challenging the Liberal Nation-State? Postnationalism, Multiculturalism, and the Collective Claims-Making of Migrants and Ethnic Minorities in Britain and Germany Ruud Koopmans and Paul Statham

FS III 98-106 Die Stimme der Medien im politischen Prozeß - Themen und Meinungen in Pressekommentaren

Friedhelm Neidhardt, Christiane Eilders und Barbara Pfetsch

FS III 98-107 Methodenbericht zum Projekt: Die Stimme der Medien im politischen Prozeß - Themen und Meinungen in Pressekommentaren

Christiane Eilders und Albrecht Lüter

FS III 99-101 Government News Management - Strategic Communication in Comparative Perspective Barbara Pfetsch

\section{Abteilung 2 "Institutionen und sozialer Wandel"}

FS III 91-201 Ein analytisches Schema zur Klassifikation von Politikinhalten. Edeltraud Roller

FS III 93-202 Eine Metatheorie des demokratischen Prozesses. Dieter Fuchs

FS III 93-203 A Metatheory of the Democratic Process. Dieter Fuchs

FS III 93-205 Mass Media: Political Independence of Press and Broadcasting Systems. Katrin Voltmer

FS III 94-201 Democratic Transformation and the Prerequisites of Democratic Opposition in East and Central Europe.

Bernhard Wessels und Hans-Dieter Klingemann

FS III 94-202 Cultural Conditions of the Transformation to Liberal Democracies in Central and Eastern Europe.

Dieter Fuchs und Edeltraud Roller

FS III 94-206 The Evolution of Western Foreign Aid Programs.

Thomas R. Cusack und Joyce P. Kaufman

FS III 96-201 Political Science: The Discipline.

Robert E. Goodin und Hans-Dieter Klingemann

FS III 96-202 Contexts of Political Protest in Western Democracies: Political Organization and Modernity.

Edeltraud Roller und Bernhard Wessels

FS III 96-203 Problemreich und konfliktgeladen: Lokale Demokratie in Deutschland fünf Jahre nach der Vereinigung.

Thomas R. Cusack und Bernhard Weßels

FS III 96-204 Social Alliances and Coalitions: The Organizational Underpinnings of Democracy in West Germany.

Bernhard Wessels 
FS III 96-205 Abbau des Sozialstaats. Einstellungen der Bundesbürger zu Kürzungen von Sozialleistungen in den neunziger Jahren.

Edeltraud Roller

FS III 96-206 System Characteristics Matter: Empirical Evidence from Ten Representation Studies. Bernhard Wessels

FS III 96-207 Wohin geht der Wandel der demokratischen Institutionen in Deutschland? Die Entwicklung der Demokratievorstellungen der Deutschen seit ihrer Vereinigung.

Dieter Fuchs

FS III 96-208 Legislative Recruitment in Germany: Professionalization or Political Class?

Bernhard Wessels

FS III 97-201 Social Capital, Institutional Structures, and Democratic Performance: A Comparative Study of German Local Governments.

Thomas R. Cusack

FS III 97-202 The Electoral Process in the Unified Germany.

Dieter Fuchs und Robert Rohrschneider

FS III 97-203 Kriterien demokratischer Performanz in Liberalen Demokratien

Dieter Fuchs

FS III 98-201 Vom Konsens zum Dissens? Politische Ordnungspräferenzen von Eliten und Bürgern im ost-westdeutschen Vergleich.

Christian Welzel

FS III 98-202 Mapping Political Support in the 1990s: A Global Analysis.

Hans-Dieter Klingemann

FS III 98-203 Remembering the Bad Old Days: Human Rights, Economic Conditions, and Democratic Performance in Transitional Regimes.

Hans-Dieter Klingemann and Richard I. Hofferbert

FS III 98-204 The Political Culture of Unified Germany

Dieter Fuchs

FS III 99-201 Näherung oder Richtung? Der Theorienstreit der Wahlforschung aus der Sicht politischer Repräsentation.

Christian Welzel und Thomas R. Cusack

FS III 99-202 Analyzing Democratic Change and Stability: A Human Development Theory of Democracy.

Christian Welzel and Ronald Inglehart

FS III 99-203 Soziale Integration und politische Institutionen in modernen Gesellschaften.

Dieter Fuchs

FS III 99-204 Die demokratische Gemeinschaft in den USA und in Deutschland.

Dieter Fuchs

\section{Abteilung 3 "Sozialstruktur und Sozialberichterstattung"}

FS III 95-401 Wie Migranten leben. Lebensbedingungen und soziale Lage der ausländischen Bevölkerung in der Bundesrepublik.

hrsg. von Wolfgang Seifert

FS III 95-402 Familie und Erwerbsarbeit in der Bundesrepublik. Rückblick, Stand der Forschung und Design einer Lebensformentypologie.

Karin Schulze Buschoff

FS III 95-403 Erwerbsverläufe in Ostdeutschland. Einflüsse und Folgen.

Horst Berger, Thomas Bulmahn und Wilhelm Hinrichs 
FS III 95-404 Sozialberichterstattung in und für Deutschland - ein Ziel, zwei Wege? Dokumentation einer Arbeitstagung zu „Sozialreport 1994“ - „Datenreport 1994“.

hrsg. von Roland Habich, Wolfgang Zapf und Gunnar Winkler

FS III 95-406 Developments in Satisfaction Research.

Ruut Veenhoven

FS III 95-408 Ökologisierung von Lebensstilen. Argumente, Beispiele, Einflußgrößen.

Katrin Gillwald

FS III 96-401 Mobilität zur sozialen Teilhabe Älterer.

Heidrun Mollenkopf und Pia Flaschenträger

FS III 96-402 Lebenszufriedenheit im europäischen Vergleich.

Ingeborg Weller

FS III 96-403 Vereinigungsbilanzen. Die deutsche Einheit im Spiegel der Sozialwissenschaften.

Thomas Bulmahn

FS III 96-404 Happy Life-Expectancy. A comprehensive measure of quality-of-life in nations.

Ruut Veenhoven

FS III 96-405 Response Style und Response Set. Eine Längsschnittuntersuchung zu den Zufriedenheitsund Einstellungsfragen im Sozio-ökonomischen Panel.

Jörg-Peter Schräpler

FS III 96-406 Rethinking Modernization: Legacies of Parsons and Hilbert.

Edward A. Tiryakian

FS III 96-407 Wohnortwechsel zwischen den Bundesländern im Kontext der Vereinigung. Wilhelm Hinrichs

FS III 97 - 401 Ungleichheits- und Gerechtigkeitsorientierungen in modernen Wohlfahrtsstaaten. Ein Vergleich der Länder Schweden, Großbritannien und der Bundesrepublik Deutschland Steffen Mau

FS III 97 - 402 Die Sozialstruktur der DDR. Versuch einer Rekonstruktion auf der Basis einer 1987 dur4chgeführten soziologischen Untersuchung

Siegfried Grundmann

FS III 97 - 403 Lebensstile und Wohnverhältnisse

Annette Spellerberg

FS III 97 - 404 Wohnmobilität und Wohnverhältnisse in West- und Ostdeutschland Nicole Schneider

FS III 97 - 405 Privathaushalte und Haushalten in Ostdeutschland Annett Schultz

FS III 97 - 406 Ein Fall von Car Sharing: Umweltentlastung durch soziale Innovation Katrin Gillwald

FS III 97 - 407 Soziologische Forschung in der DDR. Einige Aspekte der Arbeit des Wissenschaftlichen Rates

Rudi Weidig

FS III 97 - 408 Sozialindikatorenforschung in der DDR. Wissenschaftstheoretische, forschungsorganisatorische und institutionelle Aspekte Horst Berger

FS III 97 - 409 Wohnbedingungen und ihre subjektive Wahrnehmung in Ostdeutschland 1990-97 Wilhelm Hinrichs

FS III 97 - 410 Arbeitszeiten - Wunsch und Wirklichkeit in Ost- und Westdeutschland Karin Schulze Buschoff 
FS III 97 - 411 Ein Suchen und Sichfinden im Gestern und Heute. Verändern die Ostdeutschen ihre Einstellungen und Haltungen zur Demokratie und gesellschaftlichen Mitwirkung?

Eckhard Priller

FS III 98 - 401 Inequality and Support for Redistributive Policy: One World of Post-Communism, Two Worlds of Western Capitalism?

Jan Delhey

FS III 98 - 402 Über die Möglichkeit einer kontinuierlichen und zügigen Fortsetzung des chinesischen Modernisierungsprozesses

Li Pengcheng

FS III 98 - 403 Lebensstile im Zeitvergleich: Typologien für West- und Ostdeutschland 1993 und 1996 Annette Spellerberg und Regina Berger Schmitt

FS III 98 - 404 Teilzeitbeschäftigte in Europa. Arbeitsbedingungen, Familienkontext, Motive und subjektive Bewertungen Karin Schulze Buschoff und Jana Rückert

FS III 98 - 405 Das Erwerbsverhalten von Frauen im europäischen Vergleich. Welche Faktoren beeinflussen Arbeitszeiten und Arbeitszeitwünsche?

Karin Schulze Buschoff, Inge Weller und Jana Rückert

FS III 98 - 406 Rette sich, wer kann? Die Krise der gesetzlichen Rentenversicherung und die Privatisierung der Altersvorsorge

Thomas Bulmahn

FS III 98 - 407 Taking Stock: German Unification as Reflected in the Social Sciences Thomas Bulmahn

FS III 99 - 401 Wohnsuburbanisierung am Beispiel Berlin. Ein Erklärungsrahmen Wilhelm Hinrichs

FS III 99 - 402 Income Dynamics in Three Societies. An investigation of social dynamics using „old“ and „new“ types of social indicators

Zsolt Spéder, Roland Habich

FS III 99 - 403 Inequality and Attitudes. Postcommunism, Western Capitalism and Beyond Jan Delhey

FS III 99 - 404 Social Reporting in the 1970s and 1990s Wolfgang Zapf

FS III 99 - 405 New Structures of Inequality. Some Trends of Social Change in Modernized Societies Heinz-Herbert Noll

FS III 99 - 406 Teilzeitarbeit in Schweden, Großbritannien und Deutschland. Individuelle Dynamik und Haushaltskontext im Ländervergleich

Karin Schulze Buschoff unter Mitarbeit von Jana Rückert-John

FS III 99 - 407 Komparative und nicht-komperative Ansätze zur Analyse der Europäisierung der Sozialstrukturen Bernhard Schäfers

FS III 99-408 Lebensstandard und Armut im vereinten Deutschland Petra Böhnke, Jan Delhey 
Die Arbeitspapiere können bestellt werden/The discussion papers can be ordered:

Wissenschaftszentrum Berlin für

Sozialforschung (WZB)

Pressestelle

Reichpietschufer 50

D-10785 Berlin

\begin{abstract}
Bestellungen von Arbeitspapieren: Briefmarken erbeten
Wir erbitten von allen Bestellern, die Arbeitspapiere vom WZB anfordern, eine 1 DM-Briefmarke pro Papier als pauschalen Beitrag zu den anfallenden Versandkosten. Besteller aus dem Ausland werden gebeten, für jedes bestellte Arbeitspapier einen "Coupon-Réponse International" (internationalen Antwortschein), der auf Postämtern erhältlich ist, beizufügen.

Aus diesem Grund ist es auch nicht mehr möglich, Bestellungen von Arbeitspapier per Telefon oder Fax an das WZB zu richten. Schicken Sie Ihre Bestellungen nur noch schriftlich an die WZB-Pressestelle, und legen Sie neben der entsprechenden Anzahl von Briefmarken weiterhin einen mit Ihrer eigenen Adresse versehenen Aufkleber bei. Die in letzter Zeit erheblich gestiegene Anzahl von Bestellungen sowie die Mittelkürzungen, die öffentlich finanzierten Institutionen - wie auch dem WZB auferlegt wurden, machen diese Maßnahme unumgänglich. Wir bitten um Verständnis und darum, unbedingt wie beschrieben zu verfahren.
\end{abstract}

Stamps for Papers

We ask for a 1 DM-postage stamp per paper from all those who wish to order WZBpapers and who live in Germany. These stamps contribute to the shipment costs incurred. All persons interested in WZB-papers from abroad are kindly requested to send one "Coupon-Réponse International" (international reply coupon) for each ordered paper. The coupons can be obtained at your local post office.

The reasons for these measures are the high increase in the number of ordered papers during the last months as well as the cut in funds imposed on publicly financed institutions like the WZB. We do ask for your understanding and hope that you will comply with the above mentioned procedure. 